\title{
Reduced Incidence of Hepatic Encephalopathy and Higher Odds of Resolution Associated With Eradication of HCV Infection
}

\author{
Elliot B. Tapper, ${ }^{*, \neq}$ Neehar D. Parikh, ${ }^{*}$ Pamela K. Green, ${ }^{\S}$ Kristin Berry, ${ }^{\S}$ \\ Akbar K. Waljee, ${ }^{, \neq}$Andrew M. Moon, and George N. loannou ${ }^{\S, \eta, *}$
}

${ }^{*}$ Division of Gastroenterology and Hepatology, University of Michigan Health System; ${ }^{\ddagger}$ Division of Gastroenterology, Ann Arbor Veterans Administration, Ann Arbor, Michigan; ${ }^{\S}$ Research and Development, Veterans Affairs Puget Sound Healthcare System, Seattle, Washington; "Division of Gastroenterology, Department of Medicine, University of North Carolina, Chapel Hill, North Carolina; and "Division of Gastroenterology, Department of Medicine, Veterans Affairs Puget Sound Healthcare System and University of Washington, Seattle, Washington

BACKGROUND \& AIMS: It is unclear whether a sustained virologic response (SVR) to direct-acting antiviral (DAA) therapy reduces the risk of incident hepatic encephalopathy (HE) in patients with hepatitis C virus (HCV) infection or whether it leads to resolution of pre-existent HE.

METHODS:

We identified 71,457 patients who initiated antiviral treatments in the Veterans Affairs Healthcare System from January 1, 1999 through December 31, 2015; 35,871 patients (58\%) received only interferon, 4535 patients $(7.2 \%)$ received DAAs plus interferon, and 21,948 patients $(35 \%)$ received DAA-only regimens. We collected data from patients through October 31 , 2018, for an average of 6.6 years. We evaluated the association between SVR and the development of incident HE or the resolution of pre-existent HE (defined by cessation of pharmacotherapy) as well as the risk of hospitalization with HE after adjusting for potential confounders.

RESULTS:

Compared to no SVR, SVR after DAA therapy was associated with a significantly lower risk of developing HE (0.28 vs 1.39 per 100 person-years; adjusted hazard ratio [AHR] 0.41; 95\% CI, 0.32-0.51). This association persisted among patients with co-morbid alcohol use disorder and diabetes as well as patients with cirrhosis (AHR, 0.36; 95\% CI, 0.31-0.43) and model for endstage liver disease (MELD) scores of 9 or more (AHR, 0.36; 95\% CI, 0.30-0.44). SVR was also associated with reduced risk of hospitalization with HE (AHR, 0.59; 95\% CI, 0.43-0.81). Among 2396 patients who were receiving pharmacotherapy for $\mathrm{HE}$ at the time of antiviral treatment, SVR was associated with a significantly increased likelihood of HE resolution for those with MELD scores below 9 (AHR, 2.26; 95\% CI, 1.74-2.93) but not those with MELD scores of 9 or more.

CONCLUSIONS:

In a retrospective study of veterans, we found DAA eradication of $\mathrm{HCV}$ infection to be associated with a 59\% reduction in risk of development of $\mathrm{HE}$ and a $>2$-fold increased likelihood of resolution of pre-existing HE in all subgroups except patients with MELD scores of 9 or more.

Keywords: Cirrhosis; Liver Disease; Alcohol; Diabetes.

U epatitis $\mathrm{C}$ virus (HCV) is now curable in most 1 patients after a short course of direct-acting antiviral (DAA) therapy. ${ }^{1}$ Following HCV eradication, patients with cirrhosis can experience dramatic improvements in liver function and short-term outcomes. $^{2-4}$ In conjunction with earlier observational data from the pre-DAA era, these short-term improvements suggest that curing HCV may reduce the long-term risk of progressive disease and cirrhosis complications. ${ }^{5}$ However, controversy persists. Given the short followup of randomized-controlled trials, some have argued that the long-term clinical benefits of antiviral treatment and sustained virologic response (SVR) have not yet been demonstrated. ${ }^{6}$ It is therefore imperative to continue to

Abbreviations used in this paper: AHR, adjusted hazard ratio; $\mathrm{Cl}$, confidence interval; DAA, direct-acting antiviral; HCV, hepatitis C virus; HE, hepatic encephalopathy; ICD, International Classification of Diseases; IFN, interferon; MELD, model for end-stage liver disease; SVR, sustained virologic response; VA, Veterans Affairs. 
evaluate the long-term benefits of DAA-induced SVR in observational studies.

Clinicians caring for patients with cirrhosis wish to eradicate HCV to prevent, ameliorate, or reverse the complications of cirrhosis. Among the complications of cirrhosis, none is more devastating than hepatic encephalopathy (HE). ${ }^{7}$ HE increases the risk of mortality, hospitalization, falls, and other injurious accidents while simultaneously diminishing quality of life for patients and their caregivers. ${ }^{8,9}$ Interventions that prevent or resolve HE would offer substantial value in improving the morbidity and public health footprint of cirrhosis. Data are lacking regarding the effectiveness of DAA therapy with respect to either the prevention of incident $\mathrm{HE}$ or the resolution of pre-existent HE.

We aimed to determine the associations between HCV eradication and the development of incident HE or the resolution of pre-existent $\mathrm{HE}$ and to investigate such factors as disease severity and comorbidities that modify these associations in the Veterans Affairs (VA) Healthcare System.

\section{Methods}

\section{Data Source}

The VA Healthcare System is the largest integrated health care provider of HCV antiviral treatment in the United States. ${ }^{10}$ The VA uses a single comprehensive electronic health care information network that integrates all care applications into a single, common database. We obtained data on all patients who initiated antiviral therapy for chronic HCV in the VA system using the VA Corporate Data Warehouse, a national, continually updated repository of all aspects of health care data. ${ }^{11}$ The study was approved by the Institutional Review Board of the VA Puget Sound Healthcare System.

\section{Study Population}

We identified all HCV antiviral regimens $(\mathrm{n}=105,362$ regimens in 78,940 patients) initiated in the VA during 17 calendar years from January 1, 1999, to December 31, 2015. We defined SVR as a serum HCV RNA viral load test below the lower limit of detection performed at least 12 weeks after the end of HCV treatment. ${ }^{12}$ We excluded 6071 patients (7821 regimens) with missing SVR data, and 1412 patients (2452 regimens) with a prior liver transplant. The remaining 71,457 patients $(95,089$ regimens) were included in the study, including 2396 patients (2815 regimens) who were receiving $\mathrm{HE}$ pharmacotherapy at the time of antiviral treatment and 3627 patients (4813 regimens) who developed HE after antiviral therapy. The antiviral regimens are detailed in Supplementary Table 1.

\section{What You Need to Know}

\section{Background}

It is unclear whether a sustained virologic response (SVR) to direct-acting antiviral (DAA) therapy reduces the risk of incident hepatic encephalopathy (HE) in patients with hepatitis C virus (HCV) infection or whether it leads to resolution of pre-existent HE.

\section{Findings}

In a retrospective study of veterans, we found DAA eradication of HCV infection to be associated with a $56 \%$ reduction in risk of development of $\mathrm{HE}$ and a > 2 -fold increased likelihood of resolution of preexisting HE in all subgroups except patients with MELD scores of 9 or more

\section{Implications for patient care}

Patients with HCV infection should receive DAA therapy even if they have alcohol-use disorder, diabetes, cirrhosis, or HE. HCV eradication reduces risk of HE.

\section{Outcome Measures}

We explored 3 outcomes (Figure 1): (1) development of incident HE during follow-up after antiviral treatment, among patients without evidence of HE before antiviral treatment; (2) resolution of $\mathrm{HE}$, among patients who were receiving HE pharmacotherapy at the time they underwent antiviral treatment; and (3) hospitalization for HE. We evaluated the risk of hospitalization with HE and the number of hospitalizations for HE in the 3 years following therapy for those without baseline HE and those with treated HE at the time of HCV therapy.

We defined any history of HE before antiviral treatment by the presence of diagnostic codes for HE (International Classification of Diseases [ICD]-9 code 572.2 or ICD-10 code K72.91 or G93.40) recorded at least twice or use of lactulose, rifaximin, or neomycin (for a duration of $>90$ days) at any point before antiviral therapy or up to 90 days after initiation of antiviral therapy.

Incident HE was defined among patients without prior HE (defined as previously) if identified for the first time at least 90 days after initiation of antiviral treatment based on ICD-9 code 572.2 or ICD-10 code K72.91 or G93.40 recorded at least twice or the prescription of lactulose, rifaximin, or neomycin for a duration $\geq 90$ days (less if death or transplantation occurred before 90 days), whichever came first. The specificity for HE of the ICD-9 code 572.2 is $95 \%-99 \%{ }^{13}$ As previously studied, ${ }^{14}$ we maximized sensitivity for incident HE using pharmacy linkage for the prescription of medications that are specific for HE therapy. Whereas chronic rifaximin or neomycin use has limited-to-no indications other than HE, lactulose is only rarely used for constipation. 
No recorded diagnoses of HE (ICD-9 572.2, ICD-10 K72.91 or G93.40) or use of lactulose, rifaximin, or neomycin prior to HCV therapy. No Prior HE

\section{Prior Treated HE}

On treatment with lactulose, rifaximin or neomycin $\geq 90$ days at the time of $\mathrm{HCV}$ treatment
Is HCV eradication associated with the risk of incident HE?

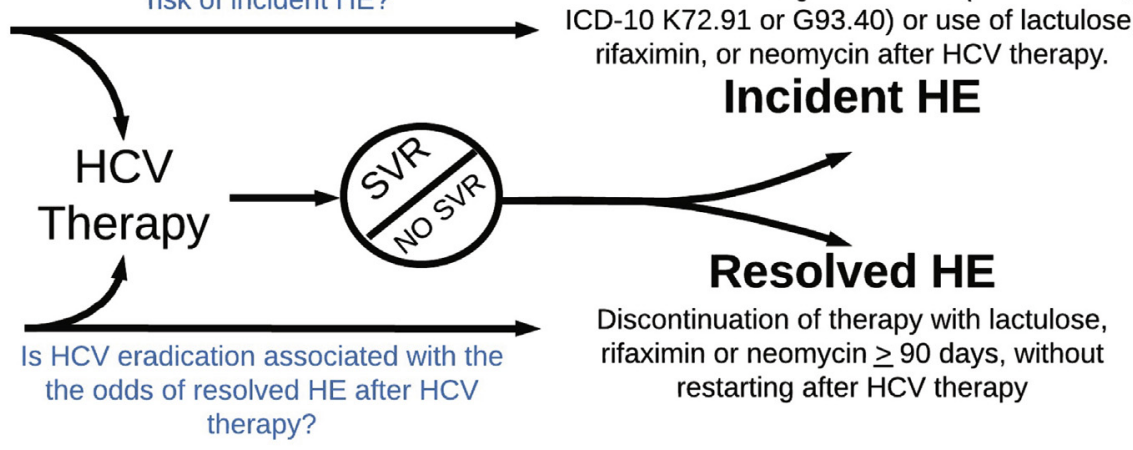

New recorded diagnosis of HE (ICD-9 572.2, CD-10 K72.91 or G93.40) or use of lactulose Incident HE

Figure 1. Study outcomes and definitions.
To test the effect of antiviral therapy on resolution of $\mathrm{HE}$, we focused exclusively on patients with prior HE who were receiving pharmacologic therapy for HE at the time of their antiviral treatment, defined by prescriptions for lactulose, rifaximin, or neomycin covering any time of the period 90 days before or after antiviral initiation, for durations $\geq 90$ days. Resolved HE was defined as the cessation of prescription fills for HE therapy for $\geq 90$ days without reinitiation of HE therapy at some point after antiviral treatment.

\section{Baseline Patient Characteristics}

We collected baseline data including age, sex, race/ ethnicity, diabetes, body mass index, HCV genotype, HCV viral load, and receipt of prior antiviral treatment. We extracted all clinical factors and laboratory tests before treatment and recorded the value of each test closest to the treatment starting date within the preceding 6 months. We defined hepatitis B virus coinfection by positive hepatitis B virus surface antigen or viral load. We also determined the presence of cirrhosis, decompensated cirrhosis (ascites, encephalopathy, gastroesophageal varices and hepatorenal syndrome), type 2 diabetes mellitus, alcohol use disorders, and substance use disorders, based on appropriate, validated ICD-9 or ICD-10 codes recorded at least twice before treatment initiation in any inpatient or outpatient encounter. ${ }^{15}$ The model for end-stage liver disease (MELD) was calculated as previously described. ${ }^{16}$

\section{Statistical Analysis}

Association between sustained virologic response and incident hepatic encephalopathy risk. We used Cox proportional hazards regression to compare patients who achieved SVR with those who did not achieve SVR with respect to the risk of developing HE. We performed multivariable adjustment and, in the supplement, a propensity-matched analysis (using inverse probability weighting for SVR) and a Fine-Gray model to account for the competing risk of death. We also performed multiple Landmark analyses to account for immortal-time bias, varying cohort entry from 0-90-365 days and end-oftherapy. Adjustment for potential confounders that may be associated with both SVR and the risk of progressive liver disease and HE included type of antiviral treatment, demographics, hepatic and extrahepatic comorbidities, and liver disease severity (laboratory values and decompensations). Continuous variables were categorized and modeled as dummy categorical variables.

Follow-up for HE incidence extended until October 31,2018 , so that even the patients treated in late 2015 (ie, the most recent in our cohort) would have substantial follow-up. Patients without incident $\mathrm{HE}$ were censored at the time of death or last follow-up in the VA. We presented subgroup analyses according to baseline variables that were associated with progressive liver disease including markers of disease severity (MELD score, in increments of 3), alcohol use disorders, diabetes, treatment regimens, and the era of antiviral therapy.

Survival analyses are stratified by the VA facility at which the antiviral treatment was administered. All treatments received by a patient during the study period were analyzed. A significant proportion (23.8\%) of patients received more than 1 antiviral treatment. Patients who did not achieve SVR were censored at initiation of a subsequent regimen that led to SVR, if applicable. The intragroup correlation induced by clustering within patient was accounted for by using robust variance estimation. Hospitalizations after HCV treatment were modelled as time-to-event (Cox models) and hospitalizations within 3 years of HCV therapy (negative binomial regression).

Association between sustained virologic response and resolution of hepatic encephalopathy. Among patients with pharmacologically treated HE at baseline (defined as previously), we used multivariable Cox proportional hazards regression to determine the association between SVR and resolution of HE (ie, cessation of pharmacotherapy) following antiviral treatment after adjusting for potential confounders, as described previously. 


\section{Results}

\section{Characteristics of Study Population}

All demographics and clinical characteristics are detailed Table 1. Compared with patients treated with interferon (IFN) only, those treated with DAA only were older and more likely to have cirrhosis, hepatocellular carcinoma, and alcohol use or substance use disorders. Overall, patients who achieved SVR were less likely to have diabetes, cirrhosis, or decompensated cirrhosis.

\section{Association Between Sustained Virologic Response and Incident Hepatic Encephalopathy}

Restricting the treated population to patients without prior HE, we evaluated the impact of SVR on the incidence of HE. During a mean follow-up of 6.6 years after antiviral treatment, 3627 out of 71,457 patients developed HE (incidence, 0.77 per 100 patient- years). The timing of HE with respect to treatment initiation is described in Supplementary Table 2. The cumulative incidence of HE was lower in patients who achieved SVR compared with those who did not (Figure 2A), irrespective of treatment regimen (Figure 2B). Although SVR is associated with a lower cumulative incidence and adjusted risk of HE for the 16,395 patients with cirrhosis (adjusted hazard ratio [AHR], 0.36; 95\% confidence interval [CI], 0.31-0.43), they still experience a substantial residual risk of HE (Figure 2C). The reduced risk of HE was present for all regimen types. Effect estimates were similar independent of sex; comorbid liver diseases, such as diabetes and alcohol use disorder; and all baseline MELD scores (Table 2). These results are also robust to multiple landmark analyses, varying cohort entry from 0-90-365 from the end-of-therapy, propensity matching, and competing-risks analysis (Supplementary Tables 3-5). These analyses are further illustrated in cumulative incidence curves using the matched populations in Supplementary Figure $1 A-C$.

When the risk of HE-related hospitalization was examined (Supplementary Table 6) we found

Table 1. Baseline Characteristics of HCV-Infected Patients Who Received Their First Antiviral Treatment From 1999-2015 According to Whether They Achieved SVR

\begin{tabular}{|c|c|c|c|c|c|c|c|}
\hline & \multirow{2}{*}{$\begin{array}{c}\text { Clinical variable } \\
\text { All patients } \\
(\mathrm{N}=71,457)\end{array}$} & \multicolumn{2}{|c|}{ IFN only } & \multicolumn{2}{|c|}{$\mathrm{DAA}+\mathrm{IFN}$} & \multicolumn{2}{|c|}{ DAA only } \\
\hline & & $\begin{array}{c}\text { No SVR } \\
(n=26,406)\end{array}$ & $\begin{array}{c}\text { SVR } \\
(\mathrm{n}=14,457)\end{array}$ & $\begin{array}{c}\text { No SVR } \\
(n=1860)\end{array}$ & $\begin{array}{c}\text { SVR } \\
(n=2883)\end{array}$ & $\begin{array}{c}\text { No SVR } \\
(n=2658)\end{array}$ & $\begin{array}{c}\text { SVR } \\
(n=22,193)\end{array}$ \\
\hline Age, $y$ (mean [SD]) & $55.8(7.8)$ & $52.4(6.4)$ & $52.1(6.8)$ & $57.7(5.9)$ & $57.3(6.7)$ & $60.5(6.9)$ & $61.0(6.7)$ \\
\hline BMI (mean [SD]) & $28.2(5.3)$ & $28.4(5.2)$ & $28.2(5.2)$ & $28.6(5.3)$ & $28.3(5.0)$ & $28.5(5.8)$ & $27.9(5.4)$ \\
\hline Male, \% & 96.6 & 96.9 & 95.7 & 95.6 & 96.4 & 98.2 & 96.6 \\
\hline \multicolumn{8}{|l|}{ Race/ethnicity, \% } \\
\hline White, non-Hispanic & 55.6 & 52.1 & 67.2 & 50 & 60 & 52.7 & 52.6 \\
\hline Black, non-Hispanic & 26 & 26 & 12.5 & 36.3 & 25.8 & 31.2 & 33 \\
\hline Hispanic & 5.9 & 6.8 & 5.9 & 6.1 & 4.4 & 6.7 & 4.9 \\
\hline Other & 1.7 & 1.7 & 1.9 & 1.5 & 1.4 & 2 & 1.7 \\
\hline Declined to answer/missing & 10.8 & 13.4 & 12.5 & 6.1 & 8.4 & 7.4 & 7.8 \\
\hline Nongenotype 1, \% & 27.9 & 27.2 & 57.3 & 1.3 & 4.9 & 27.9 & 15.4 \\
\hline HBV coinfection, $\%$ & 1 & 0.6 & 1 & 1.7 & 1.8 & 0.9 & 1.3 \\
\hline Cirrhosis, \% & 16.5 & 12.7 & 7 & 28.6 & 21.1 & 36.2 & 22.8 \\
\hline Decompensated cirrhosis, \% & 4.3 & 3.6 & 1.8 & 6.6 & 3.8 & 13.2 & 5.6 \\
\hline Ascites, \% & 0.5 & 0.7 & 0.4 & 0.1 & 0.1 & 0.6 & 0.4 \\
\hline Varices, \% & 3.5 & 2.2 & 0.9 & 6.6 & 3.4 & 12.9 & 5.4 \\
\hline Hepatocellular carcinoma & 1.2 & 0.3 & 0.3 & 1.7 & 1 & 6.3 & 2.2 \\
\hline Diabetes, \% & 21.4 & 19.2 & 13.4 & 25.3 & 20.4 & 31.9 & 27.4 \\
\hline Alcohol use disorder, $\%$ & 38.6 & 34.7 & 33.8 & 41.9 & 40.7 & 50.8 & 44.2 \\
\hline Substance use disorder, $\%$ & 31.4 & 27.1 & 26.2 & 34.8 & 32.7 & 41.5 & 37.9 \\
\hline \multicolumn{8}{|l|}{ Laboratory results, mean (SD) } \\
\hline$\alpha$-Fetoprotein, $n g / m L$ & $5.8(4.1)$ & $6.1(4.2)$ & $4.6(3.2)$ & $7.8(4.8)$ & $6.0(4.1)$ & $7.1(4.6)$ & $6.0(4.2)$ \\
\hline Hemoglobin, g/dL & $14.8(1.5)$ & $15.0(1.5)$ & $15.1(1.4)$ & $14.9(1.4)$ & $15.0(1.4)$ & $14.3(1.7)$ & $14.5(1.6)$ \\
\hline Platelet count, $k / \mu L$ & $192.2(72.4)$ & $197.4(73.6)$ & $210.9(69.2)$ & $174.0(64.6)$ & $187.9(63.5)$ & $159.0(74.2)$ & $181.1(70.7)$ \\
\hline Creatinine, $m g / d L$ & $1.0(0.6)$ & $1.0(0.7)$ & $1.0(0.4)$ & $1.0(0.7)$ & $0.9(0.3)$ & $1.0(0.4)$ & $1.0(0.5)$ \\
\hline Bilirubin, $g / d L$ & $0.7(0.5)$ & $0.7(0.5)$ & $0.6(0.4)$ & $0.7(0.4)$ & $0.6(0.4)$ & $0.8(0.7)$ & $0.7(0.5)$ \\
\hline Albumin, $g / d L$ & $4.0(0.5)$ & $4.0(0.4)$ & $4.1(0.4)$ & $3.9(0.5)$ & $4.0(0.4)$ & $3.7(0.6)$ & $3.9(0.5)$ \\
\hline INR & $1.1(1.0)$ & $1.1(0.9)$ & $1.1(1.0)$ & $1.2(1.3)$ & $1.2(1.1)$ & $1.2(1.0)$ & $1.2(0.9)$ \\
\hline MELD & $8.0(3.1)$ & $7.9(3.0)$ & $7.6(2.7)$ & $7.9(3.4)$ & $7.6(3.1)$ & $8.6(3.4)$ & $8.3(3.4)$ \\
\hline
\end{tabular}




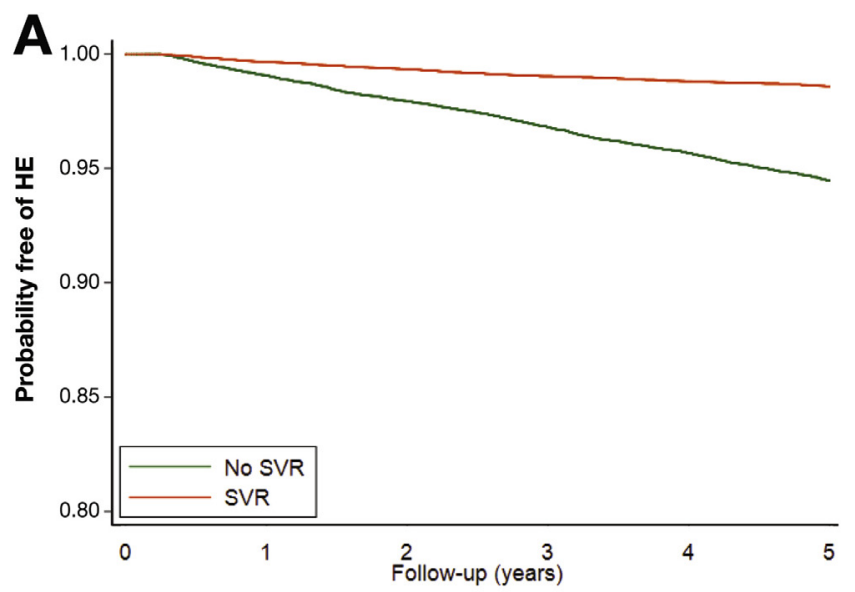

B
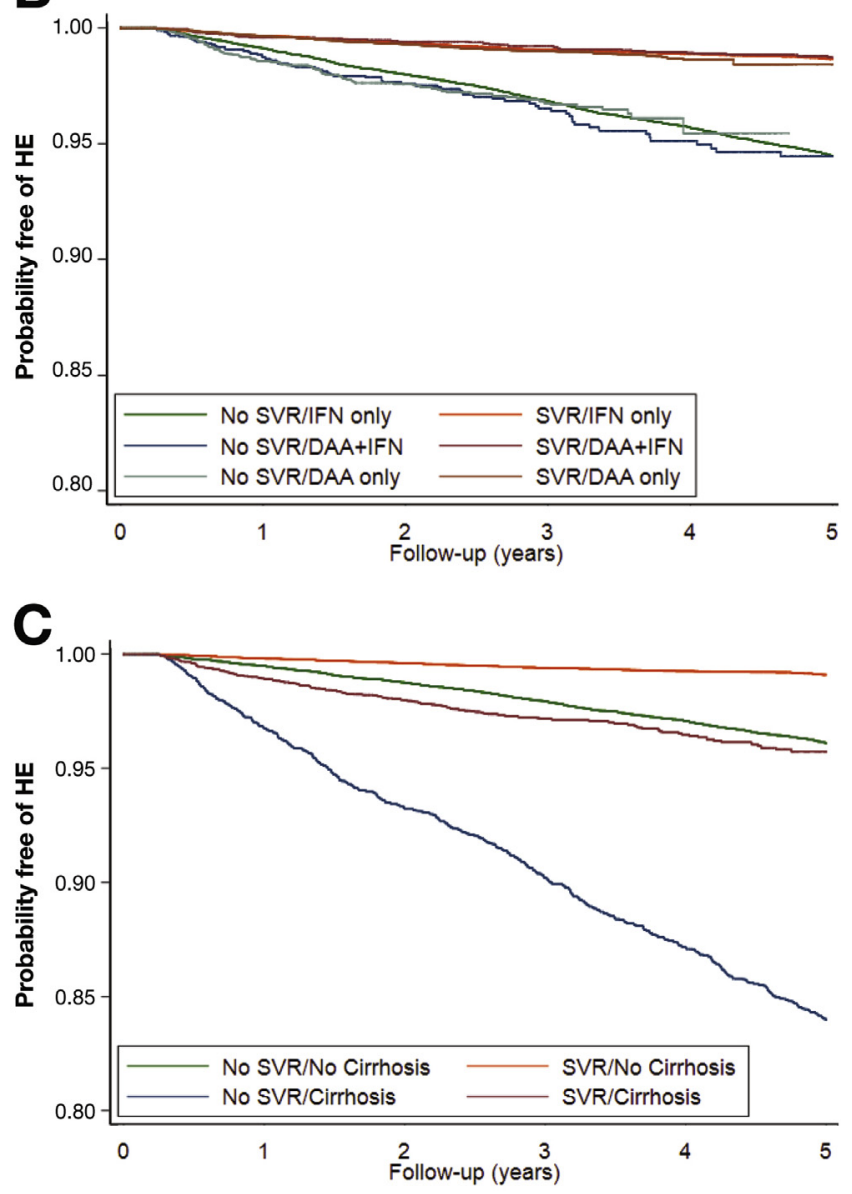

Figure 2. Kaplan-Meier curves comparing the cumulative incidence of HE development in patients who achieved SVR versus those who did not, among all patients or clinically relevant subgroups. $(A)$ All patients. $(B)$ According to antiviral regimen. $(C)$ According to presence/absence of cirrhosis.

substantially reduced risk of a first-hospitalization after SVR for all treatment types. For example, DAA-alone was associated with an AHR of 0.59 (95\% CI, 0.43-0.81). In Supplementary Table 7, we examine the total number of HE-related hospitalizations in the 3 years following HCV therapy. Again SVR is associated with reduced risk of hospitalization, adjusted incidence-rate ratio of 0.70 (95\% CI, 0.52-0.94).

\section{Association Between Sustained Virologic Response and Resolution of Hepatic Encephalopathy}

Among 2396 patients who were receiving HE pharmacotherapy at the time of antiviral treatment, 881 (36.8\%) achieved HE resolution (defined as cessation of pharmacotherapy) during a mean follow-up of 3.1 years after antiviral treatment. Patients who achieved SVR were significantly more likely to experience resolution of HE than patients who did not achieve SVR (AHR, 1.61; 95\% CI, 1.24-2.10) (Table 3, Figure 3A). SVR was associated with a higher likelihood of HE resolution among many clinically relevant subgroups, such as patients with and without diabetes and alcohol use disorder. These data were consistent irrespective of the specific treatment used for HE. IFN-induced SVR seemed to be more strongly associated with HE resolution (AHR, 2.10; 95\% CI, 1.57-2.82) than DAA + IFN-induced SVR (AHR, 1.39; 95\% CI, 0.60-3.18) or DAA-induced SVR (AHR, 1.39; 95\% CI, 1.03-1.87) (Table 3, Figure 3B). SVR was also associated with a higher likelihood of $\mathrm{HE}$ resolution among patients with MELD <9 (AHR, 2.26; 95\% CI, 1.74-2.93) but, importantly, not among patients with MELD $\geq 9$ (AHR, 1.16; 95\%, 0.84-1.60) (Figure 3C). However, we suspect that DAA-induced SVR is associated with a lower effect estimate because these therapies were used in a sicker population. Indeed, when the subset of patients with MELD $<9$ who received DAA was examined, SVR was associated with an AHR for the resolution of $\mathrm{HE}$ of 2.20 (95\% CI, 1.36-3.57). After propensity matching in Supplementary Table 8, SVR remained associated with resolved HE after IFN; however, the CI widened for DAA-alone (AHR, 1.28; 95\% CI, 0.95-1.74). Conversely, when accounting for the competing risk of death in Supplementary Table 9, the association between SVR and resolved HE strengthened (AHR, 1.51; 95\% CI, 1.13-2.01). These relationships are further illustrated in the cumulative incidence curves in Supplementary Figure $2 A-C$.

We next evaluated the impact of SVR on time-tohospitalization (Supplementary Table 10) and the total number of hospitalizations after HCV therapy (Supplementary Table 11) for patients with treated HE at baseline. We find that SVR is associated with reduced risk of first-hospitalization for IFN (AHR, 0.53; 95\% CI, 0.35-0.83) but not DAA (AHR, 0.79; 95\% CI, 0.57-1.10). Similar trends are seen for the total burden of hospitalizations with respective incidence-rate ratio for IFN and DAA of 0.28 (95\% CI, 0.19-0.41) and 0.80 (95\% CI, $0.60-1.07)$.

\section{Discussion}

Long-term data regarding the impact of HCV eradication on important clinical outcomes are limited among real-world patients. Of particular importance is the risk 
Table 2. Association Between SVR and the Risk of Developing Incident HE

\begin{tabular}{|c|c|c|c|c|c|c|c|}
\hline & $\begin{array}{l}\text { Clinical } \\
\text { variable }\end{array}$ & $\begin{array}{l}\text { Number of } \\
\text { patients (\%) }\end{array}$ & $\begin{array}{c}\text { Mean } \\
\text { follow-up } \\
(y)\end{array}$ & $\begin{array}{c}\text { Number who } \\
\text { developed } \\
\text { HE }(\%)\end{array}$ & $\begin{array}{l}\text { HE incidence } \\
\text { per } 100 \\
\text { patient-years }\end{array}$ & $\begin{array}{l}\text { Crude hazard } \\
\text { ratio }(95 \% \mathrm{Cl})\end{array}$ & $\begin{array}{c}\text { Adjusted } \\
\text { hazard ratio } \\
(95 \% \mathrm{Cl})\end{array}$ \\
\hline \multirow[t]{2}{*}{ IFN-only regimens } & No SVR & $34,006(66.7)$ & 8.6 & $3,613(10.6)$ & 1.24 & 1 & 1 \\
\hline & SVR & 16,973 (33.3) & 10.6 & $508(3.0)$ & 0.28 & $0.23(0.21-0.26)$ & $0.26(0.23-0.30)$ \\
\hline \multirow{2}{*}{$\begin{array}{r}\mathrm{DAA}+\mathrm{IFN} \\
\text { regimens }\end{array}$} & No SVR & 3198 (42.4) & 3.3 & $132(4.1)$ & 1.26 & 1 & 1 \\
\hline & SVR & 4345 (57.6) & 5.2 & $74(1.7)$ & 0.33 & $0.27(0.20-0.37)$ & $0.31(0.22-0.43)$ \\
\hline \multirow[t]{2}{*}{ DAA-only regimens } & No SVR & $3336(10.2)$ & 2.7 & $124(3.7)$ & 1.39 & 1 & 1 \\
\hline & SVR & $29,414(89.8)$ & 3.2 & $362(1.2)$ & 0.39 & $0.28(0.22-0.35)$ & $0.41(0.32-0.51)$ \\
\hline \multirow[t]{2}{*}{ Cirrhosis } & No SVR & $6940(42.3)$ & 5.2 & $1302(18.8)$ & 3.6 & 1 & 1 \\
\hline & SVR & $9455(57.7)$ & 4.2 & 419 (4.4) & 1.05 & $0.29(0.25-0.32)$ & $0.36(0.31-0.43)$ \\
\hline \multirow[t]{2}{*}{ No cirrhosis } & No SVR & $33,600(44.9)$ & 8.2 & 2567 (7.6) & 0.93 & 1 & 1 \\
\hline & SVR & 41,277 (55.1) & 6.2 & $525(1.3)$ & 0.2 & $0.23(0.20-0.25)$ & $0.25(0.22-0.28)$ \\
\hline \multirow[t]{2}{*}{ Men } & No SVR & 39,311 (44.6) & 7.7 & $3771(9.6)$ & 1.25 & 1 & 1 \\
\hline & SVR & $48,862(55.4)$ & 5.8 & 905 (1.9) & 0.32 & $0.25(0.23-0.28)$ & $0.26(0.23-0.28)$ \\
\hline \multirow[t]{2}{*}{ Women } & No SVR & 1209 (39.5) & 8.2 & $91(7.5)$ & 0.91 & 1 & 1 \\
\hline & SVR & $1855(60.5)$ & 6.4 & $39(2.1)$ & 0.33 & $0.34(0.22-0.51)$ & $0.35(0.20-0.62)$ \\
\hline \multirow[t]{2}{*}{ Diabetes } & No SVR & $8800(42.9)$ & 6.9 & 936 (10.6) & 1.55 & 1 & 1 \\
\hline & SVR & $11,731(57.1)$ & 4.7 & $288(2.5)$ & 0.52 & $0.33(0.29-0.39)$ & $0.36(0.30-0.44)$ \\
\hline \multirow[t]{2}{*}{ No diabetes } & No SVR & 31,740 (44.9) & 7.9 & 2933 (9.2) & 1.17 & 1 & 1 \\
\hline & SVR & 39,001 (55.1) & 6.2 & $656(1.7)$ & 0.27 & $0.23(0.21-0.26)$ & $0.26(0.23-0.30)$ \\
\hline \multirow[t]{2}{*}{ Alcohol use disorder } & No SVR & 14,647 (42.0) & 7.0 & $1393(9.5)$ & 1.36 & 1 & 1 \\
\hline & SVR & $20,226(58.0)$ & 5.3 & $406(2.0)$ & 0.38 & $0.27(0.24-0.31)$ & $0.31(0.27-0.37)$ \\
\hline \multirow{2}{*}{$\begin{array}{l}\text { No alcohol use } \\
\text { disorder }\end{array}$} & No SVR & 25,893 (45.9) & 8.1 & $2476(9.6)$ & 1.19 & 1 & 1 \\
\hline & SVR & $30,506(54.1)$ & 6.2 & $538(1.8)$ & 0.28 & $0.24(0.22-0.27)$ & $0.27(0.23-0.31)$ \\
\hline \multirow[t]{2}{*}{ Pre-2009 } & No SVR & $27,308(68.5)$ & 9.4 & $3216(11.8)$ & 1.25 & 1 & 1 \\
\hline & SVR & $12,583(31.5)$ & 11.8 & 407 (3.2) & 0.27 & $0.22(0.20-0.25)$ & $0.25(0.21-0.29)$ \\
\hline \multirow[t]{2}{*}{ 2009-2015 } & No SVR & $13,232(25.8)$ & 4.1 & $653(4.9)$ & 1.19 & 1 & 1 \\
\hline & SVR & $38,149(74.2)$ & 3.9 & $537(1.4)$ & 0.36 & $0.29(0.26-0.33)$ & $0.30(0.26-0.34)$ \\
\hline \multirow[t]{2}{*}{ MELD $<9$} & No SVR & $28,555(43.0)$ & 7.6 & 2348 (8.2) & 1.08 & 1 & 1 \\
\hline & SVR & $37,820(57.0)$ & 5.7 & $552(1.5)$ & 0.25 & $0.24(0.22-0.27)$ & $0.27(0.24-0.30)$ \\
\hline \multirow[t]{2}{*}{ MELD $\geq 9$} & No SVR & 4759 (42.4) & 6.2 & 765 (16.1) & 2.6 & 1 & 1 \\
\hline & SVR & 6455 (57.6) & 4.7 & $246(3.8)$ & 0.82 & $0.29(0.25-0.34)$ & $0.36(0.30-0.44)$ \\
\hline \multirow[t]{2}{*}{ MELD $\geq 12$} & No SVR & $1881(39.8)$ & 5.5 & $303(16.1)$ & 2.92 & 1 & 1 \\
\hline & SVR & $2849(60.2)$ & 4.2 & $126(4.4)$ & 1.06 & $0.34(0.27-0.42)$ & $0.39(0.29-0.52)$ \\
\hline \multirow[t]{2}{*}{ MELD $\geq 15$} & No SVR & $860(38.6)$ & 5.8 & $100(11.6)$ & 2.02 & 1 & 1 \\
\hline & SVR & $1366(61.4)$ & 4.3 & $47(3.4)$ & 0.8 & $0.39(0.26-0.58)$ & $0.48(0.30-0.76)$ \\
\hline \multirow[t]{2}{*}{ MELD $\geq 18$} & No SVR & $591(42.1)$ & 6.0 & $66(11.2)$ & 1.87 & 1 & 1 \\
\hline & SVR & $812(57.9)$ & 4.4 & $19(2.3)$ & 0.53 & $0.29(0.17-0.49)$ & $0.30(0.14-0.61)$ \\
\hline \multirow[t]{2}{*}{ MELD $\geq 21$} & No SVR & $304(41.7)$ & 6.3 & $31(10.2)$ & 1.63 & 1 & 1 \\
\hline & SVR & $425(58.3)$ & 4.8 & $8(1.9)$ & 0.39 & $0.25(0.11-0.56)$ & $0.34(0.09-1.26)$ \\
\hline
\end{tabular}

$\mathrm{Cl}$, confidence interval; DAA, direct-acting antivirals; HE, hepatic encephalopathy; IFN, interferon; MELD, model for end-stage liver disease; SVR, sustained virologic response.

${ }^{a}$ Adjusted for regimen type, cirrhosis, decompensated cirrhosis, age, sex, race/ethnicity, body mass index, hepatitis B virus coinfection, type 2 diabetes mellitus, ascites, varices, hepatocellular carcinoma, alcohol use disorders, substance use disorder, platelet count, serum bilirubin, serum creatinine, serum albumin, international normalized ratio, and blood hemoglobin levels. The laboratory tests were categorized into quartiles and modeled as dummy categorical variables.

of HE. HE is a watershed moment in the natural history of chronic HCV, one after which morbidity and mortality sharply rises. ${ }^{8,9,17-19}$ Accordingly, there are broad societal benefits tied to interventions that can prevent or resolve HE. To evaluate the impact of SVR on the risk of $\mathrm{HE}$, we examined a very large sample from the VA Healthcare System $(>70,000$ patients, including roughly 25,000 who received DAA only) with long-term followup ( $>6.5$ years per-person). We show that SVR after DAA therapy is associated with a $59 \%$ reduction in the risk of incident $\mathrm{HE}$ and a $41 \%$ reduction in the risk of hospitalization with HE. When HE is present at the time of therapy, SVR is associated with a $61 \%$ increased rate of HE resolution.

\section{Sustained Virologic Response Reduces the Risk of Hepatic Encephalopathy}

Intensive therapy for HE is associated with inconsistent benefits. Even patients receiving optimal treatment experience breakthrough episodes and diminished quality of life. ${ }^{20,21}$ Treating the underlying liver disease in the hope of forestalling or reducing further progression to cirrhosis and $\mathrm{HE}$ is therefore the best option to reduce HE-related risks. Our data suggest that SVR is associated with a dramatic reduction in the risk of developing HE. This includes reductions of $75 \%$ for those without cirrhosis at baseline; $64 \%$ for those with cirrhosis; and equivalent reductions for those with 
Table 3. Association Between SVR and Resolution of HE

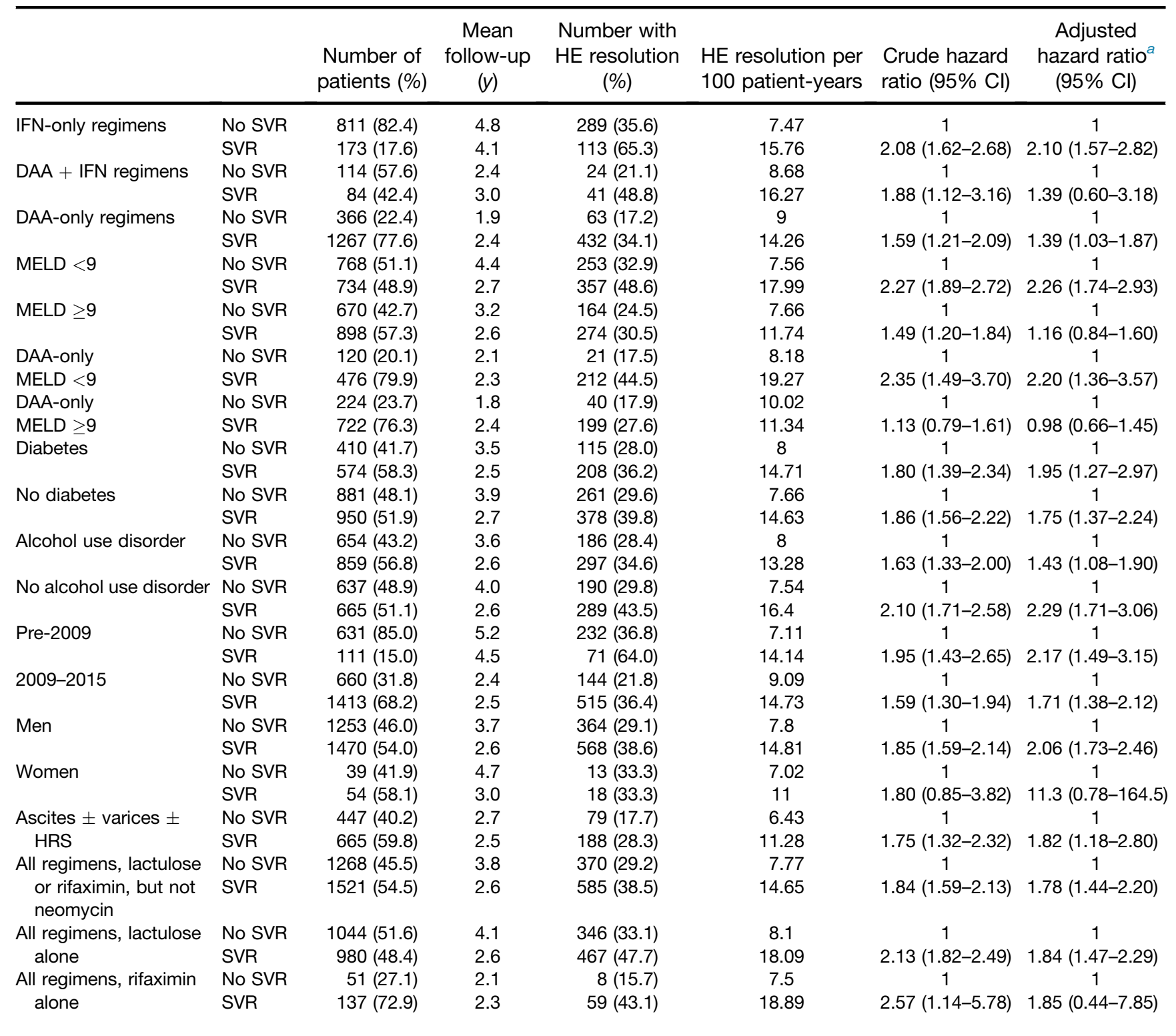

$\mathrm{Cl}$, confidence interval; DAA, direct-acting antivirals; HE, hepatic encephalopathy; HRS, hepatorenal syndrome; IFN, interferon; MELD, model for end-stage liver disease; SVR, sustained virologic response.

${ }^{a}$ Adjusted for regimen type, cirrhosis, decompensated cirrhosis, age, sex, race/ethnicity, body mass index, hepatitis B virus coinfection, type 2 diabetes mellitus, ascites, varices, hepatocellular carcinoma, alcohol use disorders, substance use disorder, platelet count, serum bilirubin, serum creatinine, serum albumin, international normalized ratio, and blood hemoglobin levels. The laboratory tests were categorized into quartiles and modeled as dummy categorical variables.

MELD $\geq 9$, comorbid alcohol use disorder, and diabetes. These data are bolstered further by a marked reduction in the risk and overall burden of hospitalization with HE.

\section{Sustained Virologic Response Increases the Likelihood of Hepatic Encephalopathy Resolution}

After an episode of overt HE, especially after repeated episodes, ${ }^{22}$ it is unclear whether it is possible to safely discontinue HE therapy without risk of recurrence. Guidelines from the American Association for the Study of Liver Disease acknowledge that data are lacking for this important question but suggest that if liver function improves substantially, a trial of treatment discontinuation could be considered. ${ }^{22}$ Addressing this gap, we add novel data to show that among patients with treated HE at the time of HCV therapy, SVR is associated with a significantly increased likelihood of successfully discontinuing HE therapy without recurrence, particularly for patients with MELD score $<9$. SVR is also associated with fewer hospitalizations with HE. Unfortunately, patients with MELD $>9$ do not experience this benefit after SVR, suggesting that 

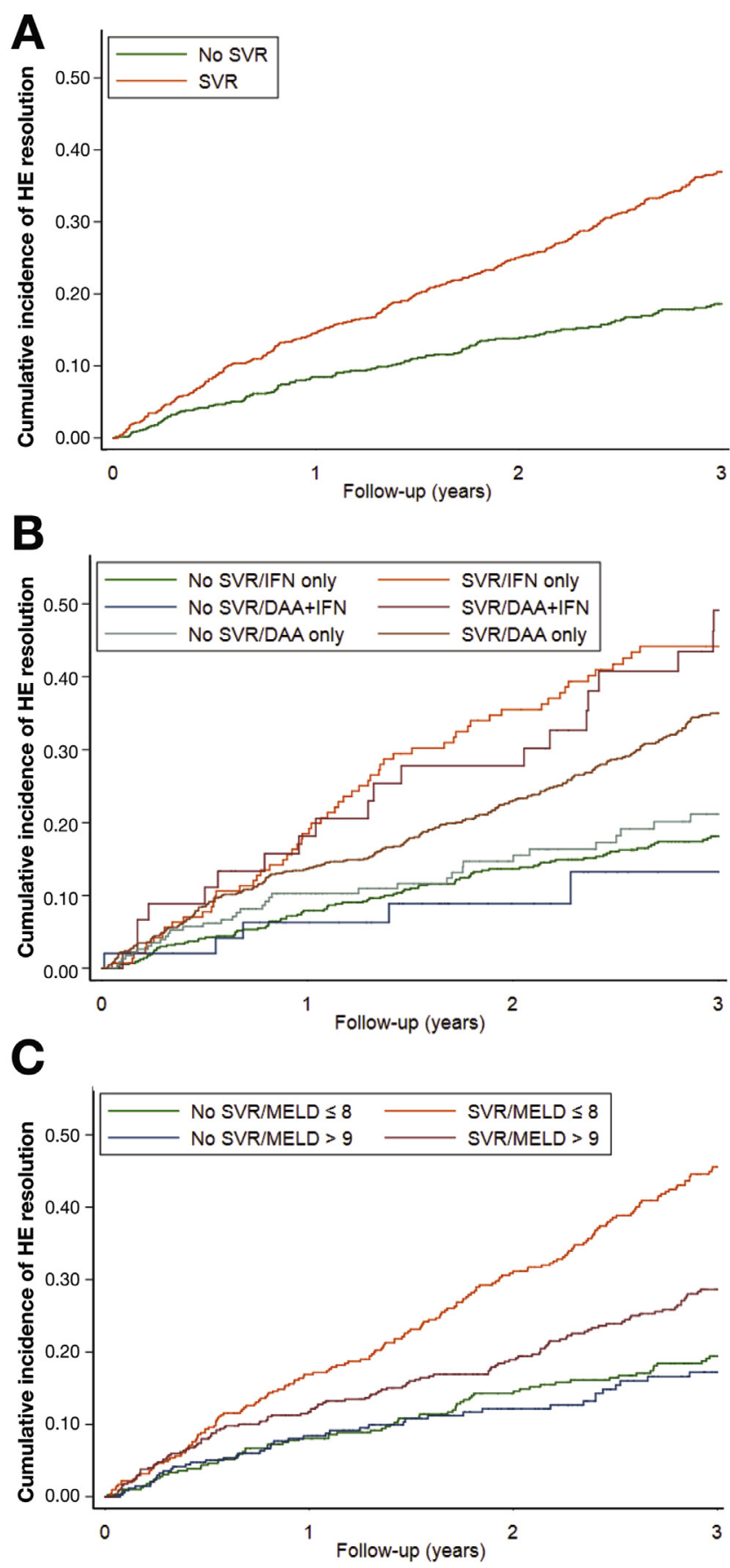

Figure 3. Cumulative probability curves comparing the resolution of HE in patients with SVR versus those without SVR among all patients or clinically relevant subgroups. (A) All patients. $(B)$ By antiviral regimen. $(C)$ By MELD category.

there is a disease severity threshold after which freedom from HE therapy is unlikely. It is known that SVR is associated with improved quality of life. ${ }^{23}$ Minimal HE is associated with and may even be confused for poor patient-reported outcomes. Accordingly, the reasons underlying the clinical decision to discontinue HE therapy are challenging to discern even prospectively. It is clear, however, that SVR was associated with durably discontinuing HE therapy.

\section{What Is Known About the Risk of Hepatic Encephalopathy After Hepatitis C Virus Therapy?}

Our findings extend the data on the impact of HCV therapy on HE risk in multiple ways. First, we demonstrate a reduced risk of HE after DAA-induced SVR (and IFN-induced SVR) in a contemporary dataset with long follow-up, after adjustment for liver disease severity and comorbid liver diseases, such as diabetes and alcohol use disorder. This dataset is also the largest to explore the association of SVR with HE. Previously, van der Meer et $\mathrm{al}^{5}$ showed that after HCV therapy, 11 (2.7\%) patients without SVR developed overt HE in follow-up compared with 0 (of 125) matched patients with SVR. Because the decision to use IFN and IFN-associated SVR are both associated with favorable baseline characteristics that may also be associated with lower risk of developing HE, our adjusted DAA-associated outcomes are likely more applicable to today's patients with HCV. Clinical trials of DAA in compensated patients or those with early liver disease lack sufficient follow-up to determine associations with HE risk. Two clinical trials of DAAs have included patients with decompensated cirrhosis, both of which demonstrated improved MELD and Child-Pugh scores but lacked long-term follow-up beyond 24 weeks. ${ }^{3,4}$

Second, we show that SVR is associated with increased likelihood of a durable long-term resolution of HE defined by cessation of HE therapy for all patients save for those with MELD scores $\geq 9$. These data extend a recently published combined analysis of the trials of sofosbuvir-based DAA therapy in patients with decompensated cirrhosis. El-Sherif et $\mathrm{al}^{2}$ showed that subjects with HE were among those least likely to benefit from DAA therapy after 12-24 weeks of follow-up. These authors demonstrated that those with HE at baseline were most likely to experience the suboptimal outcome known as "MELD purgatory" whereby their MELD would improve (to $<15$ ) but they would retain persistent HE. $^{2,24}$ Our study's design of much longer follow-up (3.14 years vs 24 weeks) and sensitive outcome determination (cessation of therapy) is more broadly applicable to real-world patients. Although SVR was associated with reduced HE-related hospitalizations, the association was not statistically significant when evaluating DAAs separately.

\section{Limitations}

These data must be interpreted in the context of the study design. First, patients were derived from a single, national health care system with fairly uniform antiviral treatment practices and guidelines across its facilities. Second, because this is by necessity an observational study (patients cannot be randomized to eradication or not and cannot ethically be randomized to antiviral 
treatment versus no treatment, especially with long-term follow-up) we cannot exclude the possibility that residual confounding may have contributed to the associations we observed between SVR and prevention or resolution of HE. However, the associations persisted after careful adjustment for 20 baseline characteristics known or suspected to be associated with SVR and HE. Furthermore, the associations persisted across almost all subgroups, except for the lack of association between SVR and HE resolution among patients with MELD score $\geq 9$, which is biologically plausible and enhances the internal validity of the study. Third, we defined resolved $\mathrm{HE}$ as the cessation of therapy (without reinitiation during follow-up), if overt HE recurred (particularly in patients who previously received HE-therapy) they would likely universally have been restarted on HE therapy. We cannot, with these data, determine whether patients with "resolved HE" retained cognitive dysfunction or minimal HE. Fourth and similarly, we only measured diagnosed HE (using diagnostic codes and medical therapy). Because we did not assess cognition, these data do not evaluate the risk of minimal HE or changes in cognitive performance after HCV therapy. Finally, the definition of HE was based in part on chronic lactulose use. Some patients may be placed on this medication exclusively to treat constipation and not HE.

\section{Conclusions}

These data from a large cohort of patients undergoing HCV therapy, including roughly 25,000 who received DAA alone, with and without cirrhosis, and who were followed for many years after therapy demonstrates 2 core benefits associated with SVR. First, patients achieving SVR are significantly less likely to experience incident HE. Second, for patients with actively treated HE at the time of HCV therapy, SVR is associated with significantly improved likelihood of HE resolution for all clinically relevant subgroups except patients with MELD $\geq 9$. Taken together, these data demonstrate a specific benefit of HCV therapy and one that may reduce the national burden of HE and its related complications.

\section{Supplementary Material}

Note: To access the supplementary material accompanying this article, visit the online version of Clinical Gastroenterology and Hepatology at www.cghjournal.org, and at https://doi.org/10.1016/j.cgh.2019.09.033.

\section{References}

1. Pawlotsky J-M, Feld JJ, Zeuzem S, et al. From non-A, non-B hepatitis to hepatitis C virus cure. J Hepatol 2015;62:S87-S99.

2. El-Sherif O, Jiang Z, Tapper E, et al. Baseline factors associated with improvements in decompensated cirrhosis after directacting antiviral therapy for HCV infection. Gastroenterology 2018;154:2111-2121.
3. Curry MP, O'Leary JG, Bzowej N, et al. Sofosbuvir and velpatasvir for HCV in patients with decompensated cirrhosis. N Engl J Med 2015;373:2618-2628.

4. Charlton M, Everson GT, Flamm SL, et al. Ledipasvir and sofosbuvir plus ribavirin for treatment of HCV infection in patients with advanced liver disease. Gastroenterology 2015; 149:649-659.

5. van der Meer AJ, Veldt BJ, Feld JJ, et al. Association between sustained virological response and all-cause mortality among patients with chronic hepatitis $\mathrm{C}$ and advanced hepatic fibrosis. JAMA 2012;308:2584-2593.

6. Jakobsen J, Nielsen E, Feinberg J, et al. Direct-acting antivirals for chronic hepatitis C. Cochrane Database Syst Rev 2017; 6:CD012143.

7. Tapper EB, Jiang ZG, Patwardhan VR. Refining the ammonia hypothesis: a physiology-driven approach to the treatment of hepatic encephalopathy. Mayo Clin Proc 2015;646-658.

8. Bajaj JS, Saeian K, Schubert CM, et al. Minimal hepatic encephalopathy is associated with motor vehicle crashes: the reality beyond the driving test. Hepatology 2009;50:1175-1183.

9. Ezaz G, Murphy SL, Mellinger J, et al. Increased morbidity and mortality associated with falls among patients with cirrhosis. Am J Med 2018;131:645-650.

10. Moon AM, Green PK, Berry K, et al. Transformation of hepatitis $\mathrm{C}$ antiviral treatment in a national healthcare system following the introduction of direct antiviral agents. Aliment Pharmacol Ther 2017; 45:1201-1212.

11. Veterans Affairs Corporate Data Warehouse. Available at: http:// www.hsrd.research.va.gov/for_researchers/vinci/cdw.cfm Date. Accessed December 19, 2016.

12. Yoshida EM, Sulkowski MS, Gane EJ, et al. Concordance of sustained virological response 4, 12, and 24 weeks posttreatment with sofosbuvir-containing regimens for hepatitis C virus. Hepatology 2015;61:41-45.

13. Nehra MS, Ma Y, Clark C, et al. Use of administrative claims data for identifying patients with cirrhosis. J Clin Gastroenterol 2013;47:e50.

14. Tapper EB, Parikh N, Sengupta N, et al. A risk score to predict the development of hepatic encephalopathy in a populationbased cohort of patients with cirrhosis. Hepatology 2017; 68:1498-1507.

15. Kanwal F, Hoang T, Kramer JR, et al. Increasing prevalence of HCC and cirrhosis in patients with chronic hepatitis C virus infection. Gastroenterology 2011;140:1182-1188.

16. Kim WR, Biggins SW, Kremers WK, et al. Hyponatremia and mortality among patients on the liver-transplant waiting list. N Engl J Med 2008;359:1018-1026.

17. Tapper E, Kanwal F, Asrani S, et al. Patient reported outcomes in cirrhosis: a scoping review of the literature. Hepatology 2017;67:2375-2383.

18. Arguedas MR, DeLawrence TG, McGuire BM. Influence of hepatic encephalopathy on health-related quality of life in patients with cirrhosis. Dig Dis Sci 2003;48:1622-1626.

19. Tapper EB, Halbert B, Mellinger J. Rates of and Reasons for Hospital Readmissions in Patients with Cirrhosis: A Multistate Population-based Cohort Study. Clin Gastroenterol Hepatol 2016;14:1181-1188.

20. Bass NM, Mullen KD, Sanyal A, et al. Rifaximin treatment in hepatic encephalopathy. N Engl J Med 2010;362:1071-1081.

21. Tapper EB, Risech-Neyman Y, Sengupta N. Psychoactive medications increase the risk of falls and fall-related injuries in 
hospitalized patients with cirrhosis. Clin Gastroenterol Hepatol 2015;13:1670-1675.

22. Vilstrup H, Amodio P, Bajaj J, et al. Hepatic encephalopathy in chronic liver disease: 2014 Practice Guideline by the American Association for the Study of Liver Diseases and the European Association for the Study of the Liver. Hepatology 2014; 60:715-735.

23. Younossi ZM, Stepanova M, Jacobson I, et al. Not achieving sustained viral eradication of hepatitis $\mathrm{C}$ virus after treatment leads to worsening patient-reported outcomes. Clin Infect Dis 2020;7:628-632.

24. Carrion AF, Khaderi SA, Sussman NL. Model for end-stage liver disease limbo, model for end-stage liver disease purgatory, and the dilemma of treating hepatitis $\mathrm{C}$ in patients awaiting liver transplantation. Liver Transpl 2016; 22:279-280.
Reprint requests

Address requests for reprints to: George N. Ioannou, BMBCh, MS, Veterans Affairs Puget Sound Health Care System, Gastroenterology, S-111-Gastro, 1660 S. Columbian Way, Seattle, Washington 98108. e-mail: georgei@ medicine.washington.edu; fax: (206) 764-2232.

\section{Conflicts of interest}

This author discloses the following: Elliot B. Tapper has received grants from Valeant and Gilead; participated in advisory boards for Mallinckrodt and Bausch; and consulted for Novartis and Allergan. The contents do not represent the views of the US Department of Veterans Affairs or the US Government The other authors disclose no conflicts.

\section{Funding}

The study was funded by a National Institutes of Health/ $\mathrm{NCl}$ grant (R01CA196692) and VA CSR\&D grant (I01CX001156, to G.N.I.). Elliot B. Tappe receives funding from the National Institutes of Health through the Michigan Institute for Clinical and Health Research (KL2TR002241). The content is solely the responsibility of the authors and does not necessarily represent the official views of the National Institutes of Health. 

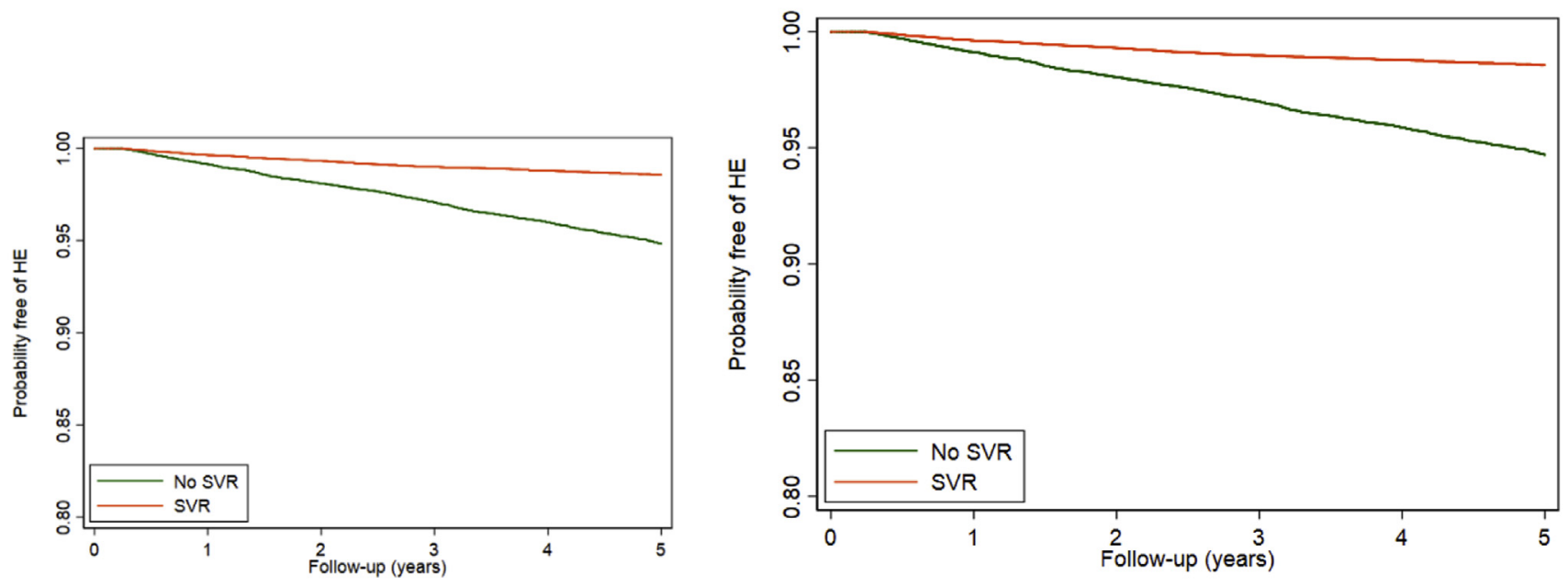

\section{B. ACCORDING TO ANTIVIRALREGIMEN}
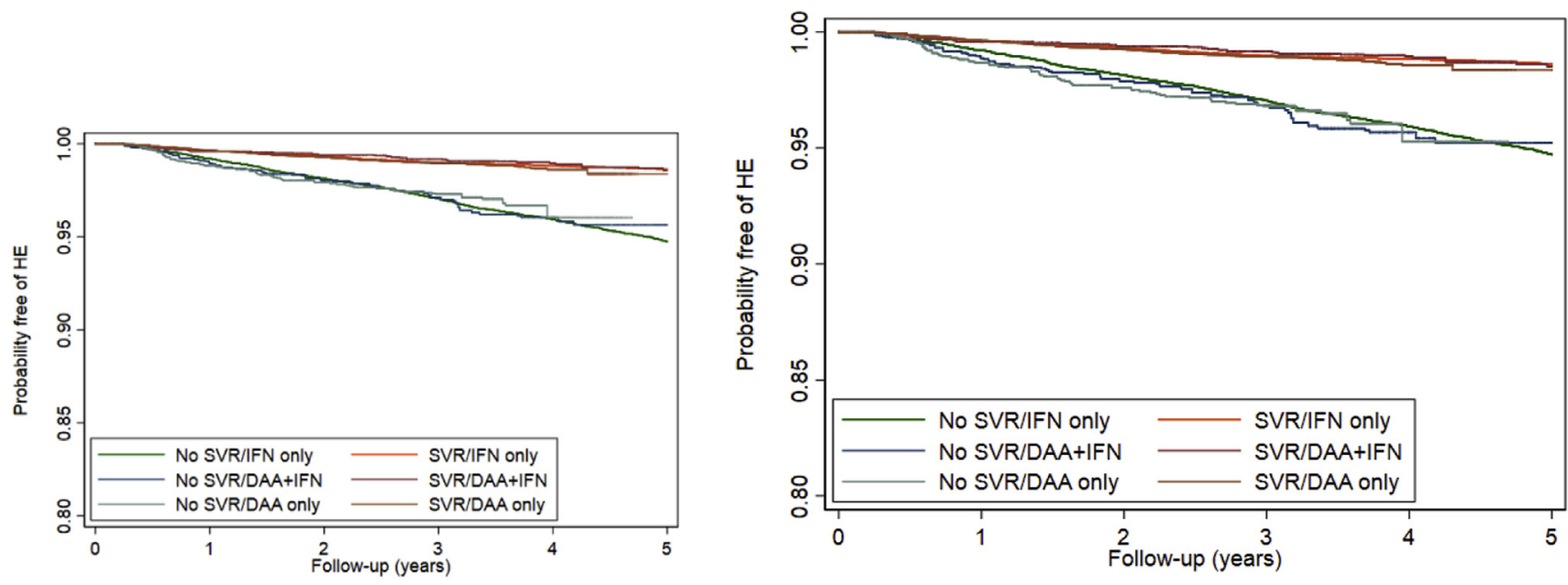

\section{ACCORDING TO PRESENCE/ABSENCE OF CIRRHOSIS}
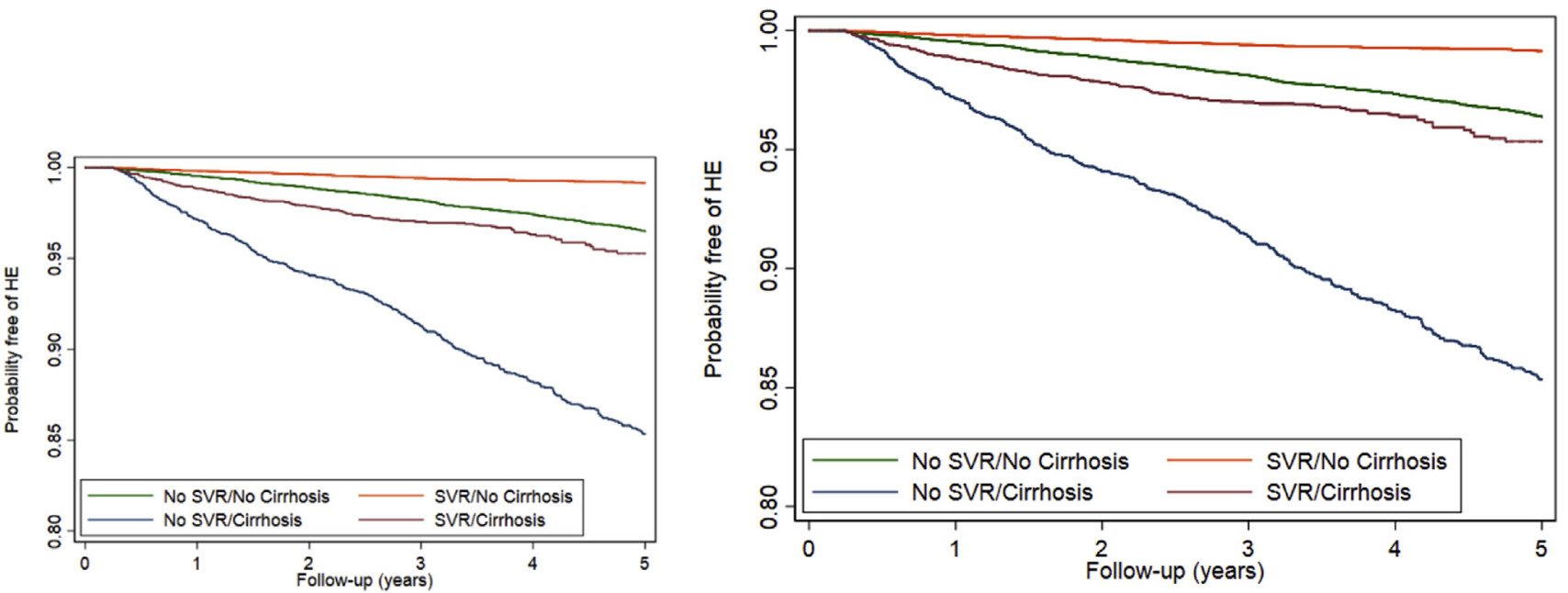

Supplementary Figure 1. Kaplan-Meier curves comparing the cumulative incidence of HE development in patients who achieved SVR versus those who did not, among all patients or clinically relevant subgroups. Left plots use inverse probability weights based on the propensity scores. Plots on the right use trimmed (largest and smallest propensity scores dropped) inverse probability weights. $(A)$ All patients. $(B)$ According to antiviral regimen. (C) According to presence/absence of cirrhosis. 


\section{A. ALL PATIENTS}
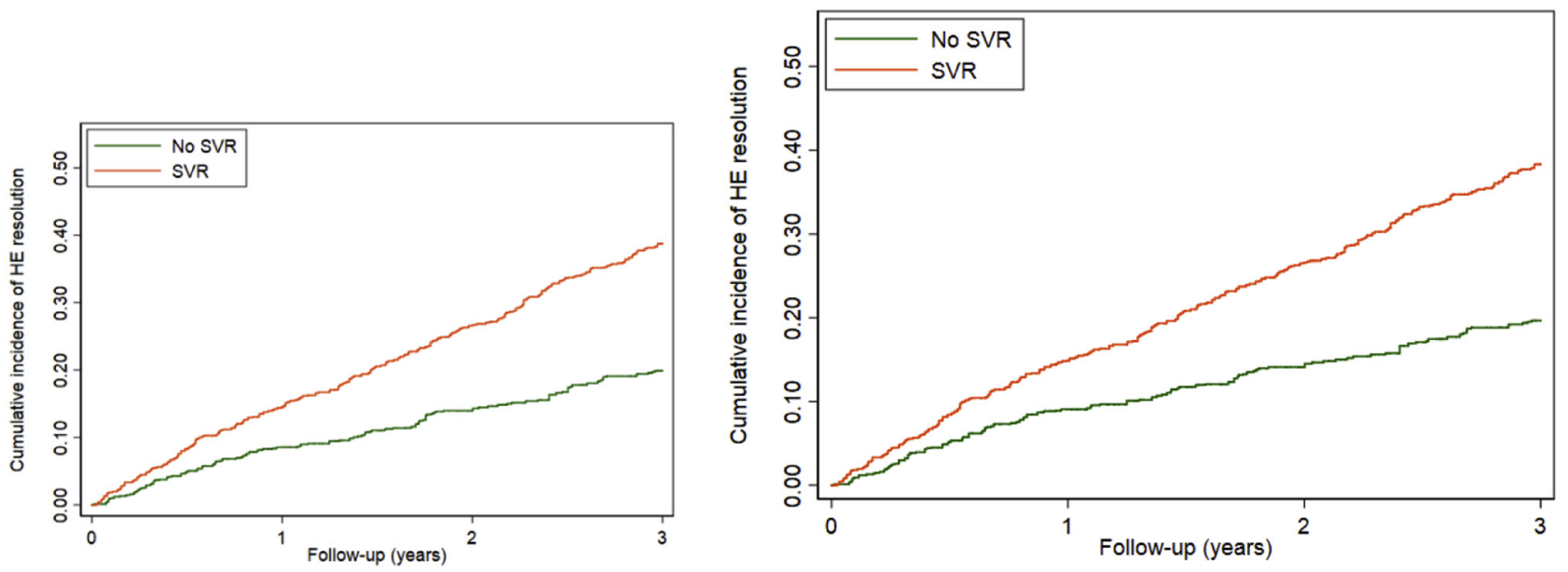

\section{B. BY ANTIVIRAL REGIMEN}
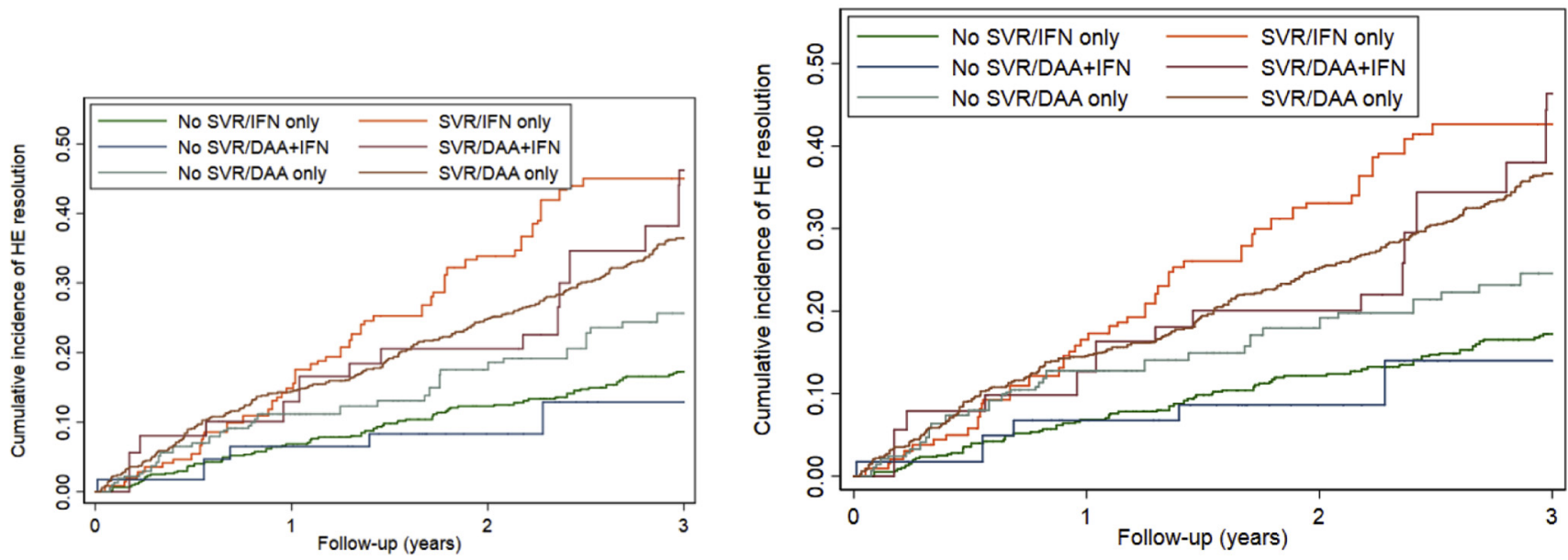

\section{BY MELD CATEGORY}
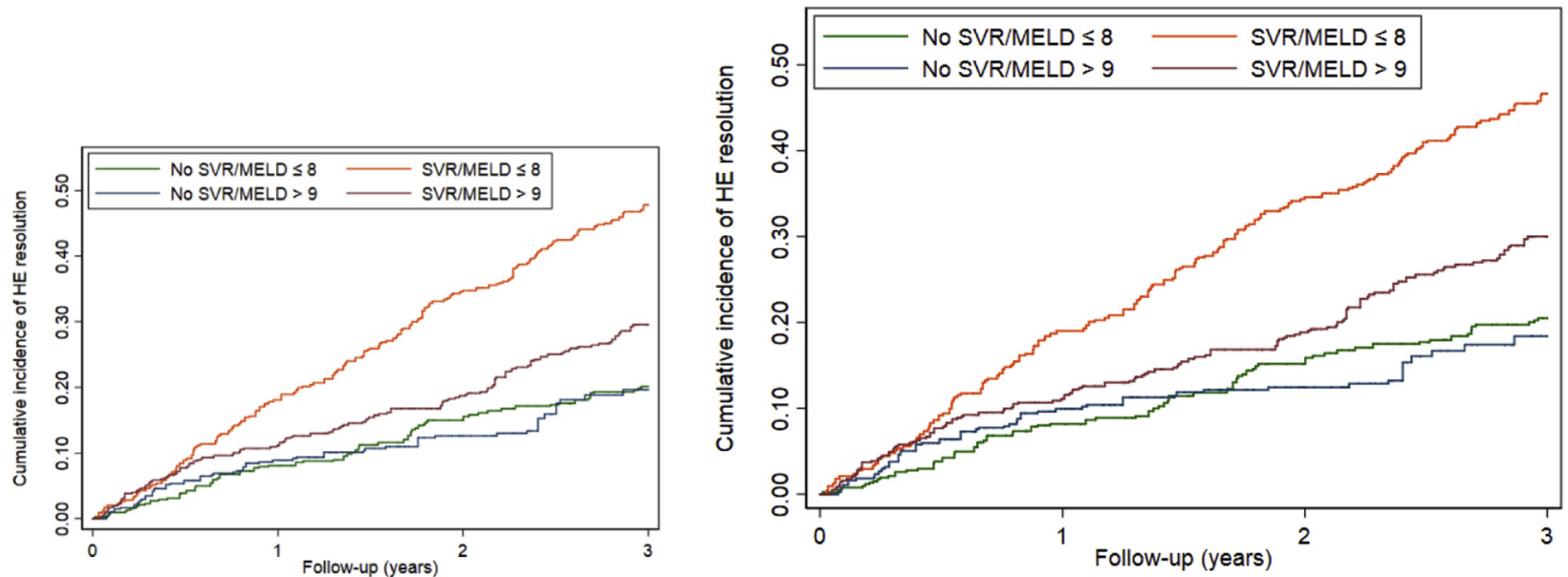

Supplementary Figure 2. Cumulative-probability curves comparing the resolution of HE in patients with SVR versus those without SVR among all patients or clinically relevant subgroups. Left plots use inverse probability weights based on the propensity scores. Plots on the right use trimmed (largest and smallest propensity scores dropped) inverse probability weights. $(A)$ All patients. $(B)$ By antiviral regimen. $(C)$ By MELD category. 
Supplementary Table 1. Types of HCV Antiviral Treatment Regimens Included in Our Study of VA Patients From 1999-2015

\begin{tabular}{|c|c|c|c|}
\hline Treatment category & Regimen $^{a}$ & First regimen, $\mathrm{n}(\%)$ & All regimens, $\mathrm{n}(\%)$ \\
\hline \multirow[t]{2}{*}{ IFN only } & Interferon & $3872(5.4)$ & $5914(6.2)$ \\
\hline & PEG & $36,991(51.8)$ & $46,245(48.6)$ \\
\hline \multirow{3}{*}{$\mathrm{DAA}+\mathrm{IFN}$} & Telaprevir + PEG & $498(0.7)$ & $997(1.0)$ \\
\hline & Simeprevir + PEG & $14(0.0)$ & $23(0.0)$ \\
\hline & Sofosbuvir + PEG & $1046(1.5)$ & $1834(1.9)$ \\
\hline \multirow{2}{*}{ DAA only } & Ledipasvir/sofosbuvir & $15,055(21.1)$ & $20,539(21.6)$ \\
\hline & Paritaprevir/ritonavir/ombitasvir/dasabuvir & $5255(7.4)$ & $6602(6.9)$ \\
\hline
\end{tabular}

DAA, direct-acting antivirals; HCV, hepatitis C virus; IFN, interferon; PEG, pegylated interferon; VA, Veterans Affairs.

${ }^{a}$ Regimens with or without ribavirin were included together.

Supplementary Table 2. Timing of HE vis-à-vis Treatment Initiation

\begin{tabular}{|c|c|c|c|c|c|}
\hline $\begin{array}{l}\text { Treatment } \\
\text { category/ } \\
\text { outcome }\end{array}$ & $\begin{array}{l}\text { Number of } \\
\text { patients who } \\
\text { developed HE } \\
\text { after start of } \\
\text { treatment }\end{array}$ & $\begin{array}{l}\text { Number who } \\
\text { developed HE } \\
\text { within } 90 \mathrm{~d} \text { of } \\
\text { start-date (\%) }\end{array}$ & $\begin{array}{c}\text { Number who } \\
\text { developed HE } \\
\text { within } 180 \mathrm{~d} \text { of start- } \\
\text { date }(\%)\end{array}$ & $\begin{array}{l}\text { Number who } \\
\text { developed HE } \\
\text { within } 360 \mathrm{~d} \text { of } \\
\text { start-date (\%) }\end{array}$ & $\begin{array}{c}\text { Number who } \\
\text { developed HE } \\
\text { before treatment end- } \\
\text { date }(\%)\end{array}$ \\
\hline IFN & 4270 & 149 (3.5) & $283(6.6)$ & $526(12.3)$ & $235(5.5)$ \\
\hline $\mathrm{IFN}+\mathrm{DAA}$ & 234 & $28(12.0)$ & $50(21.4)$ & $86(36.8)$ & $44(18.8)$ \\
\hline No SVR & 4049 & $180(4.4)$ & $321(7.9)$ & 584 (14.4) & $233(5.8)$ \\
\hline
\end{tabular}

DAA, direct-acting antivirals; HE, hepatic encephalopathy; IFN, interferon; SVR, sustained virologic response. 
Supplementary Table 3. Varying Cohort Entry Dates with Respect to Treatment Initiation Has a Limited Effect on the Risk Estimates for $\mathrm{HE}$

\begin{tabular}{|c|c|c|c|c|c|c|c|}
\hline $\begin{array}{l}\text { Treatment } \\
\text { category }\end{array}$ & $\begin{array}{l}\text { SVR } \\
\text { status }\end{array}$ & $\begin{array}{l}\text { Number of } \\
\text { patients (\%) }\end{array}$ & $\begin{array}{l}\text { Mean Follow- } \\
\text { up }(y)\end{array}$ & $\begin{array}{c}\text { Number who } \\
\text { developed HE (\%) }\end{array}$ & $\begin{array}{l}\text { HE incidence } \\
\text { per } 100 \\
\text { patient-years }\end{array}$ & $\begin{array}{l}\text { Crude hazard } \\
\text { ratio }(95 \% \mathrm{Cl})\end{array}$ & $\begin{array}{c}\text { Adjusted } \\
\text { hazard ratio }^{a} \\
(95 \% \mathrm{Cl})\end{array}$ \\
\hline \multicolumn{8}{|c|}{ Analysis starting at $90 \mathrm{~d}$ from antiviral treatment initiation } \\
\hline \multirow{2}{*}{$\begin{array}{l}\text { IFN-only } \\
\text { regimens }\end{array}$} & No SVR & $34,006(66.7)$ & 8.6 & 3,613 (10.6) & 1.24 & 1 & 1 \\
\hline & SVR & 16,973 (33.3) & 10.6 & 508 (3.0) & 0.28 & $0.23(0.21-0.26)$ & $0.26(0.23-0.30)$ \\
\hline \multirow{2}{*}{$\begin{array}{r}\mathrm{DAA}+\mathrm{IFN} \\
\text { regimens }\end{array}$} & No SVR & 3198 (42.4) & 3.3 & $132(4.1)$ & 1.26 & 1 & 1 \\
\hline & SVR & 4345 (57.6) & 5.2 & $74(1.7)$ & 0.33 & $0.27(0.20-0.37)$ & $0.31(0.22-0.43)$ \\
\hline \multirow{2}{*}{$\begin{array}{l}\text { DAA-only } \\
\text { regimens }\end{array}$} & No SVR & 3336 (10.2) & 2.7 & $124(3.7)$ & 1.39 & 1 & 1 \\
\hline & SVR & $29,414(89.8)$ & 3.2 & $362(1.2)$ & 0.39 & $0.28(0.22-0.35)$ & $0.41(0.32-0.51)$ \\
\hline \multicolumn{8}{|c|}{ Analysis starting at $180 \mathrm{~d}$ from antiviral treatment initiation } \\
\hline \multirow{2}{*}{$\begin{array}{l}\text { IFN-only } \\
\text { regimens }\end{array}$} & No SVR & $33,897(66.7)$ & 8.6 & $3504(10.3)$ & 1.2 & 1 & 1 \\
\hline & SVR & 16,948 (33.3) & 10.6 & $483(2.8)$ & 0.27 & $0.22(0.20-0.25)$ & $0.25(0.22-0.28)$ \\
\hline \multirow{2}{*}{$\begin{array}{r}\mathrm{DAA}+\mathrm{IFN} \\
\text { regimens }\end{array}$} & No SVR & $3182(42.3)$ & 3.3 & $116(3.6)$ & 1.1 & 1 & 1 \\
\hline & SVR & $4339(57.7)$ & 5.2 & $68(1.6)$ & 0.3 & $0.27(0.20-0.37)$ & $0.30(0.22-0.43)$ \\
\hline \multirow{2}{*}{$\begin{array}{l}\text { DAA-only } \\
\text { regimens }\end{array}$} & No SVR & $3320(10.2)$ & 2.7 & $108(3.3)$ & 1.21 & 1 & 1 \\
\hline & SVR & $29,370(89.8)$ & 3.2 & $318(1.1)$ & 0.34 & $0.28(0.22-0.35)$ & $0.39(0.31-0.50)$ \\
\hline \multicolumn{8}{|c|}{ Analysis starting at $360 \mathrm{~d}$ from antiviral treatment initiation } \\
\hline \multirow{2}{*}{$\begin{array}{l}\text { IFN-only } \\
\text { regimens }\end{array}$} & No SVR & $33,697(66.6)$ & 8.7 & $3304(9.8)$ & 1.13 & 1 & 1 \\
\hline & SVR & $16,905(33.4)$ & 10.6 & $440(2.6)$ & 0.24 & $0.21(0.19-0.24)$ & $0.24(0.21-0.27)$ \\
\hline \multirow{2}{*}{$\begin{array}{r}\mathrm{DAA}+\mathrm{IFN} \\
\text { regimens }\end{array}$} & No SVR & 3160 (42.2) & 3.3 & $94(3.0)$ & 0.9 & 1 & 1 \\
\hline & SVR & $4325(57.8)$ & 5.2 & $54(1.2)$ & 0.24 & $0.24(0.17-0.34)$ & $0.26(0.18-0.38)$ \\
\hline \multirow{2}{*}{$\begin{array}{l}\text { DAA-only } \\
\text { regimens }\end{array}$} & No SVR & $3279(10.1)$ & 2.7 & $67(2.0)$ & 0.75 & 1 & 1 \\
\hline & SVR & $29,295(89.9)$ & 3.2 & $243(0.8)$ & 0.26 & $0.33(0.25-0.44)$ & $0.43(0.32-0.59)$ \\
\hline \multicolumn{8}{|c|}{ Analysis starting at the time antiviral treatment was stopped } \\
\hline \multirow{2}{*}{$\begin{array}{l}\text { IFN-only } \\
\text { regimens }\end{array}$} & No SVR & $33,917(66.7)$ & 8.6 & $3524(10.4)$ & 1.21 & 1 & 1 \\
\hline & SVR & $16,943(33.3)$ & 10.6 & $478(2.8)$ & 0.27 & $0.22(0.20-0.25)$ & $0.25(0.22-0.28)$ \\
\hline \multirow{2}{*}{$\begin{array}{r}\mathrm{DAA}+\mathrm{IFN} \\
\text { regimens }\end{array}$} & No SVR & $3189(42.4)$ & 3.3 & $123(3.9)$ & 1.17 & 1 & 1 \\
\hline & SVR & 4335 (57.6) & 5.2 & $64(1.5)$ & 0.28 & $0.24(0.18-0.33)$ & $0.28(0.20-0.39)$ \\
\hline \multirow{2}{*}{$\begin{array}{l}\text { DAA-only } \\
\text { regimens }\end{array}$} & No SVR & 3335 (10.2) & 2.7 & $123(3.7)$ & 1.37 & 1 & 1 \\
\hline & SVR & 29,401 (89.8) & 3.2 & 349 (1.2) & 0.37 & $0.27(0.22-0.34)$ & $0.39(0.31-0.49)$ \\
\hline
\end{tabular}

$\mathrm{Cl}$, confidence interval; DAA, direct-acting antivirals; HE, hepatic encephalopathy; IFN, interferon; SVR, sustained virologic response.

Supplementary Table 4. Propensity Matched Analysis of the Association between SVR and the Risk of Developing Incident HE

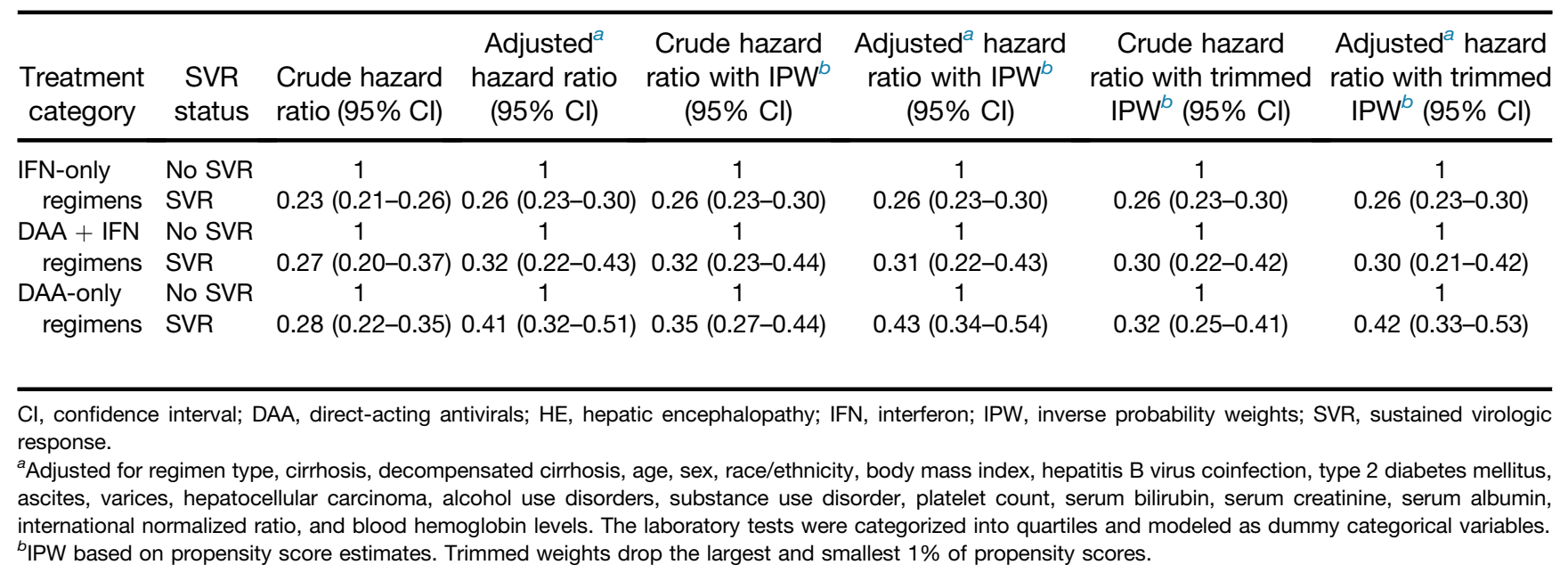


Supplementary Table 5. Association Between SVR and the Risk of Developing Incident HE Accounting for the Competing Risk of Death

\begin{tabular}{|c|c|c|c|c|c|}
\hline $\begin{array}{l}\text { Treatment } \\
\text { category }\end{array}$ & $\begin{array}{l}\text { SVR } \\
\text { status }\end{array}$ & $\begin{array}{c}\text { Crude hazard ratio } \\
(95 \% \mathrm{Cl})\end{array}$ & $\begin{array}{c}\text { Adjusted }^{a} \text { hazard ratio } \\
(95 \% \mathrm{Cl})\end{array}$ & $\begin{array}{l}\text { Crude subhazard }{ }^{b} \text { ratio } \\
(95 \% \mathrm{Cl})\end{array}$ & $\begin{array}{l}\text { Adjusted }^{a} \text { subhazard } \\
\text { ratio }(95 \% \mathrm{Cl})\end{array}$ \\
\hline \multirow{2}{*}{$\begin{array}{l}\text { IFN-only } \\
\text { regimens }\end{array}$} & No SVR & 1 & 1 & 1 & 1 \\
\hline & SVR & $0.23(0.21-0.26)$ & $0.26(0.23-0.30)$ & $0.24(0.22-0.27)$ & $0.29(0.26-0.32)$ \\
\hline \multirow{2}{*}{$\begin{array}{r}\mathrm{DAA}+\mathrm{IFN} \\
\text { regimens }\end{array}$} & No SVR & 1 & 1 & 1 & 1 \\
\hline & SVR & $0.27(0.20-0.37)$ & $0.31(0.22-0.43)$ & $0.28(0.21-0.38)$ & $0.33(0.24-0.46)$ \\
\hline \multirow{2}{*}{$\begin{array}{l}\text { DAA-only } \\
\text { regimens }\end{array}$} & No SVR & 1 & 1 & 1 & 1 \\
\hline & SVR & $0.28(0.22-0.35)$ & $0.41(0.32-0.51)$ & $0.29(0.24-0.35)$ & $0.43(0.35-0.54)$ \\
\hline
\end{tabular}

$\mathrm{Cl}$, confidence interval; DAA, direct-acting antivirals; HE, hepatic encephalopathy; IFN, interferon; SVR, sustained virologic response.

${ }^{a}$ Adjusted for regimen type, cirrhosis, decompensated cirrhosis, age, sex, race/ethnicity, body mass index, hepatitis B virus coinfection, type 2 diabetes mellitus, ascites, varices, hepatocellular carcinoma, alcohol use disorders, substance use disorder, platelet count, serum bilirubin, serum creatinine, serum albumin, international normalized ratio, and blood hemoglobin levels. The laboratory tests were categorized into quartiles and modeled as dummy categorical variables.

${ }^{b}$ With death as a competing risk.

Supplementary Table 6. Association Between SVR and the Risk of Hospitalization With HE, Among Patients Without HE at Baseline

\begin{tabular}{|c|c|c|c|c|c|c|c|}
\hline $\begin{array}{l}\text { Treatment } \\
\text { category }\end{array}$ & $\begin{array}{l}\text { SVR } \\
\text { status }\end{array}$ & $\begin{array}{l}\text { Number of } \\
\text { patients (\%) }\end{array}$ & $\begin{array}{l}\text { Mean follow- } \\
\text { up }(y)\end{array}$ & $\begin{array}{l}\text { Number who } \\
\text { were hospitalized } \\
\text { for HE }(\%)\end{array}$ & $\begin{array}{c}\text { First HE } \\
\text { hospitalization per } \\
100 \text { patient-years }\end{array}$ & $\begin{array}{l}\text { Crude hazard } \\
\text { ratio }(95 \% \mathrm{Cl})\end{array}$ & $\begin{array}{c}\text { Adjusted }^{a} \\
\text { hazard ratio } \\
(95 \% \mathrm{Cl})\end{array}$ \\
\hline \multirow{2}{*}{$\begin{array}{l}\text { IFN-only } \\
\text { regimens }\end{array}$} & No SVR & $34,006(66.7)$ & 8.9 & $1948(5.7)$ & 0.65 & 1 & 1 \\
\hline & SVR & 16,973 (33.3) & 10.7 & $292(1.7)$ & 0.16 & $0.24(0.21-0.28)$ & $0.28(0.24-0.33)$ \\
\hline \multirow{2}{*}{$\begin{array}{r}\mathrm{DAA}+\mathrm{IFN} \\
\text { regimens }\end{array}$} & No SVR & $3198(42.4)$ & 3.3 & $43(1.3)$ & 0.4 & 1 & 1 \\
\hline & SVR & $4345(57.6)$ & 5.2 & $39(0.9)$ & 0.17 & $0.39(0.26-0.61)$ & $0.43(0.26-0.70)$ \\
\hline \multirow{2}{*}{$\begin{array}{l}\text { DAA-only } \\
\text { regimens }\end{array}$} & No SVR & 3336 (10.2) & 2.7 & 54 (1.6) & 0.6 & 1 & 1 \\
\hline & SVR & $29,414(89.8)$ & 3.2 & 298 (1.0) & 0.32 & $0.52(0.38-0.70)$ & $0.59(0.43-0.81)$ \\
\hline
\end{tabular}

$\mathrm{CI}$, confidence interval; DAA, direct-acting antivirals; HE, hepatic encephalopathy; IFN, interferon; SVR, sustained virologic response.

${ }^{a}$ Adjusted for regimen type, cirrhosis, decompensated cirrhosis, age, sex, race/ethnicity, body mass index, hepatitis B virus coinfection, type 2 diabetes mellitus, ascites, varices, hepatocellular carcinoma, alcohol use disorders, substance use disorder, platelet count, serum bilirubin, serum creatinine, serum albumin, international normalized ratio, and blood hemoglobin levels. The laboratory tests were categorized into quartiles and modeled as dummy categorical variables.

Supplementary Table 7. Association Between SVR and the Number of Hospitalizations in the First 3 Years After Treatment Start, Among Patients Without HE at Baseline

\begin{tabular}{clcccc}
\hline $\begin{array}{c}\text { Treatment } \\
\text { category }\end{array}$ & $\begin{array}{c}\text { SVR } \\
\text { status }\end{array}$ & $\begin{array}{c}\text { Number of } \\
\text { patients (\%) }\end{array}$ & $\begin{array}{c}\text { Mean number of } \\
\text { hospitalizations for HE (SD) }\end{array}$ & $\begin{array}{c}\text { Incident rate ratio of } \\
\text { number of hospitalizations } \\
\text { for HE }\end{array}$ & $\begin{array}{c}\text { Adjusted } \\
\text { ratio of numbident rate } \\
\text { hospitalizations for HE }\end{array}$ \\
\hline IFN-only & No SVR & $34,006(66.7)$ & $0.14(0.77)$ & 1 & 1 \\
regimens & SVR & $16,973(33.3)$ & $0.03(0.32)$ & $0.22(0.17-0.28)$ & 1 \\
DAA + IFN & No SVR & $3198(42.4)$ & $0.03(0.29)$ & $0.34(0.21-0.55)$ & 1 \\
regimens & SVR & $4345(57.6)$ & $0.01(0.12)$ & 1 & $0.59(0.38-0.92)$ \\
DAA-only & No SVR & $3336(10.2)$ & $0.02(0.15)$ & & 1 \\
regimens & & & & & \\
\end{tabular}

DAA, direct-acting antivirals; HE, hepatic encephalopathy; IFN, interferon; SD, standard deviation; SVR, sustained virologic response. 
Supplementary Table 8. Propensity Matched Analysis of the Association Between SVR and Resolution of HE

\begin{tabular}{|c|c|c|c|c|c|c|c|}
\hline $\begin{array}{l}\text { Treatment } \\
\text { category }\end{array}$ & $\begin{array}{c}\text { SVR } \\
\text { status }\end{array}$ & $\begin{array}{l}\text { Crude hazard } \\
\text { ratio }(95 \% \mathrm{Cl})\end{array}$ & $\begin{array}{l}\text { Adjusted }^{a} \\
\text { hazard ratio } \\
(95 \% \mathrm{Cl})\end{array}$ & $\begin{array}{l}\text { Crude hazard } \\
\text { ratio with IPW } \\
(95 \% \mathrm{Cl})\end{array}$ & $\begin{array}{l}\text { Adjusted }{ }^{a} \text { hazard } \\
\text { ratio with } \mathrm{IPW}^{b} \\
(95 \% \mathrm{Cl})\end{array}$ & $\begin{array}{l}\text { Crude hazard } \\
\text { ratio with trimmed } \\
\operatorname{IPW}^{b}(95 \% \mathrm{Cl})\end{array}$ & $\begin{array}{l}\text { Adjusted }^{a} \text { hazard } \\
\text { ratio with trimmed } \\
\text { IPW }^{b}(95 \% \text { Cl) }\end{array}$ \\
\hline $\begin{array}{l}\text { IFN-only } \\
\text { regimens }\end{array}$ & $\begin{array}{l}\text { No SVR } \\
\text { SVR }\end{array}$ & $\begin{array}{c}1 \\
2.08(1.62-2.68)\end{array}$ & $\begin{array}{c}1 \\
2.10(1.57-2.82)\end{array}$ & $\begin{array}{c}1 \\
2.24(1.70-2.97)\end{array}$ & $\begin{array}{c}1 \\
2.32(1.76-3.07)\end{array}$ & $\begin{array}{c}1 \\
2.01(1.50-2.68)\end{array}$ & $\begin{array}{c}1 \\
2.09(1.55-2.81)\end{array}$ \\
\hline $\begin{array}{r}\mathrm{DAA}+\mathrm{IFN} \\
\text { regimens }\end{array}$ & $\begin{array}{l}\text { No SVR } \\
\text { SVR }\end{array}$ & $\begin{array}{c}1 \\
1.88(1.12-3.16)\end{array}$ & $\begin{array}{c}1 \\
1.39(0.60-3.18)\end{array}$ & $\begin{array}{c}1 \\
1.86(1.02-3.39)\end{array}$ & $\begin{array}{c}1 \\
1.34(0.56-3.18)\end{array}$ & $\begin{array}{c}1 \\
2.09(1.17-3.75)\end{array}$ & $\begin{array}{c}1 \\
1.39(0.58-3.30)\end{array}$ \\
\hline $\begin{array}{l}\text { DAA-only } \\
\text { regimens }\end{array}$ & $\begin{array}{l}\text { No SVR } \\
\text { SVR }\end{array}$ & $\begin{array}{c}1 \\
1.59(1.21-2.09)\end{array}$ & $\begin{array}{c}1 \\
1.39(1.03-1.87)\end{array}$ & $\begin{array}{c}1 \\
1.53(1.13-2.07)\end{array}$ & $\begin{array}{c}1 \\
1.28(0.95-1.72)\end{array}$ & $\begin{array}{c}1 \\
1.59(1.17-2.15)\end{array}$ & $\begin{array}{c}1 \\
1.28(0.95-1.74)\end{array}$ \\
\hline
\end{tabular}

Supplementary Table 9. Competing Risks (Fine-Gray) Analysis of the Association Between SVR and Resolution of HE

\begin{tabular}{|c|c|c|c|c|c|}
\hline $\begin{array}{l}\text { Treatment } \\
\text { category }\end{array}$ & $\begin{array}{l}\text { SVR } \\
\text { status }\end{array}$ & $\begin{array}{c}\text { Crude hazard ratio } \\
\qquad(95 \% \mathrm{Cl})\end{array}$ & $\begin{array}{l}\text { Adjusted }^{a} \text { hazard } \\
\text { ratio }(95 \% \mathrm{Cl})\end{array}$ & $\begin{array}{l}\text { Crude subhazard } \\
\text { ratio }(95 \% \mathrm{Cl})\end{array}$ & $\begin{array}{c}\text { Adjusted }^{a} \\
\text { subhazard }^{b} \text { ratio } \\
(95 \% \mathrm{Cl})\end{array}$ \\
\hline $\begin{array}{r}\mathrm{DAA}+\mathrm{IFN} \\
\text { regimens }\end{array}$ & $\begin{array}{l}\text { No SVR } \\
\text { SVR }\end{array}$ & $\begin{array}{c}1 \\
1.88(1.12-3.16)\end{array}$ & $\begin{array}{c}1 \\
1.39(0.60-3.18)\end{array}$ & $\begin{array}{c}1 \\
1.99(1.21-3.28)\end{array}$ & $\begin{array}{c}1 \\
1.40(0.63-3.15)\end{array}$ \\
\hline
\end{tabular}

Cl, confidence interval; DAA, direct-acting antivirals; HE, hepatic encephalopathy; IFN, interferon; SVR, sustained virologic response.

${ }^{a}$ Adjusted for regimen type, cirrhosis, decompensated cirrhosis, age, sex, race/ethnicity, body mass index, hepatitis B virus coinfection, type 2 diabetes mellitus, ascites, varices, hepatocellular carcinoma, alcohol use disorders, substance use disorder, platelet count, serum bilirubin, serum creatinine, serum albumin, international normalized ratio, and blood hemoglobin levels. The laboratory tests were categorized into quartiles and modeled as dummy categorical variables. ${ }^{b}$ With death as a competing risk. 
Supplementary Table 10. Association Between SVR and the Risk of Hospitalization With HE, Among Patients Who Were on HE Medications at Baseline

\begin{tabular}{|c|c|c|c|c|c|c|c|}
\hline $\begin{array}{l}\text { Treatment } \\
\text { category }\end{array}$ & $\begin{array}{l}\text { SVR } \\
\text { status }\end{array}$ & $\begin{array}{l}\text { Number of } \\
\text { patients (\%) }\end{array}$ & $\begin{array}{c}\text { Mean } \\
\text { follow-up } \\
(y)\end{array}$ & $\begin{array}{c}\text { Number who } \\
\text { were hospitalized } \\
\text { for HE }(\%)\end{array}$ & $\begin{array}{c}\text { First HE } \\
\text { hospitalization } \\
\text { per } 100 \text { patient- } \\
\text { years }\end{array}$ & $\begin{array}{l}\text { Crude hazard } \\
\text { ratio }(95 \% \mathrm{Cl})\end{array}$ & $\begin{array}{l}\text { Adjusted }^{a} \text { hazard } \\
\text { ratio }(95 \% \mathrm{Cl})\end{array}$ \\
\hline \multirow{2}{*}{$\begin{array}{l}\text { IFN-only } \\
\text { regimens }\end{array}$} & No SVR & 983 (83.3) & 5.9 & $239(24.3)$ & 4.12 & 1 & 1 \\
\hline & SVR & $197(16.7)$ & 8.4 & $28(14.2)$ & 1.69 & $0.44(0.28-.69)$ & $0.53(0.35-0.83)$ \\
\hline $\begin{array}{r}\mathrm{DAA}+\mathrm{IFN} \\
\text { regimens }\end{array}$ & No SVR & $167(59.9)$ & 2.8 & $25(15.0)$ & 5.37 & 1 & 1 \\
\hline $\begin{array}{l}\text { DAA-only } \\
\text { regimens }\end{array}$ & SVR & 1,861 (78.9) & 2.9 & 179 (9.6) & 3.35 & $0.67(0.49-0.91)$ & $0.79(0.57-1.10)$ \\
\hline
\end{tabular}

$\mathrm{Cl}$, confidence interval; DAA, direct-acting antivirals; $\mathrm{HE}$, hepatic encephalopathy; IFN, interferon; SVR, sustained virologic response.

${ }^{a}$ Adjusted for regimen type, cirrhosis, decompensated cirrhosis, age, sex, race/ethnicity, body mass index, hepatitis B virus coinfection, type 2 diabetes mellitus, ascites, varices, hepatocellular carcinoma, alcohol use disorders, substance use disorder, platelet count, serum bilirubin, serum creatinine, serum albumin, international normalized ratio, and blood hemoglobin levels. The laboratory tests were categorized into quartiles and modeled as dummy categorical variables.

Supplementary Table 11. Association Between SVR and Number of Hospitalizations in the First 3 Years After Treatment Start for Patients With Treated HE at Baseline

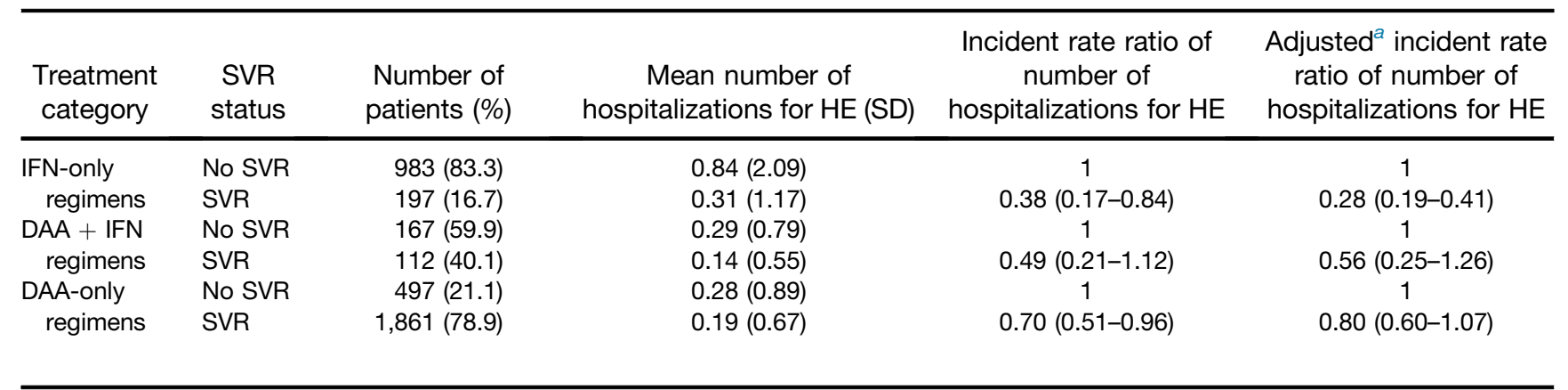

DAA, direct-acting antivirals; HE, hepatic encephalopathy; IFN, interferon; SD, standard deviation; SVR, sustained virologic response.

${ }^{a}$ Adjusted for regimen type, cirrhosis, decompensated cirrhosis, age, sex, race/ethnicity, body mass index, hepatitis B virus coinfection, type 2 diabetes mellitus, ascites, varices, hepatocellular carcinoma, alcohol use disorders, substance use disorder, platelet count, serum bilirubin, serum creatinine, serum albumin, international normalized ratio, and blood hemoglobin levels. The laboratory tests were categorized into quartiles and modeled as dummy categorical variables. 